\title{
Pd-NHC 络合物催化交叉偶联反应的新进展
}

\author{
倪 晨 ${ }^{b}$ 沈 安 ${ }^{a, b}$ 曹育才*,a,b 叶晓峰 $a, b$ \\ ( ${ }^{a}$ 上海市聚烯烃催化技术重点实验室 上海 200062) \\ $\left({ }^{b}\right.$ 上海化工研究院 有机化工研究所 上海 200062)
}

\begin{abstract}
摘要 钯催化的交叉偶联反应能非常有效且方便构建碳-碳键并应用于农药、医药、新型材料和有机中间体等领域. 多 年来, 各种不同结构的配体以及新型的催化体系被不断开发出来. 其中 $\mathrm{N}$-杂环卡宾 $(\mathrm{NHC}$ )配体毒性低, 稳定性好, 同时 在反应过程中具备良好的配位能力, 因而被作为新一代催化体系应用于各种不同的交叉偶联反应中. 根据 NHC 结构特 点综述了近年来新开发的 Pd-NHC 催化剂及其在多种交叉偶联反应中的应用.
\end{abstract}

关键词＼cjkstart钯催化剂; $\mathrm{N}$-杂环卡宾; 交叉偶联反应

\section{New Progress in Crossing Coupling Reactions Catalyzed by Pd-NHC Complexes}

\author{
Ni, Chen ${ }^{b} \quad$ Shen, $\mathrm{An}^{a, b} \quad$ Cao, Yucai ${ }^{*, a, b} \quad$ Ye, Xiaofeng ${ }^{a, b}$ \\ ( ${ }^{a}$ Shanghai Key Laboratory of Catalysis Technology for Polyolefins, Shanghai 200062) \\ ( ${ }^{b}$ Organic Chemistry Division, Shanghai Research Institute of Chemical Industry, Shanghai 200062)
}

\begin{abstract}
Palladium-catalyzed cross-coupling reaction has become one of the most powerful and convenient protocol for the construction of carbon-carbon bonds in agrochemistry, pharmaceutical chemistry, materials and synthetic chemistry. In recent years, a variety of different structures of ligands and novel catalysts have been widely explored. Wherein N-heterocyclic carbene (NHC) ligands are employed as new generation catalysts in cross-coupling reactions due to low toxicity, good stability as well as appropriate coordination ability. The application of new developed Pd-NHC catalysts in cross-coupling reactions is reviewed according to the characteristics of NHC structures.
\end{abstract}

Keywords Pd catalyst; N-heterocyclic carbene (NHC); cross-coupling reaction

钯催化交叉偶联反应是一类用于碳-碳键形成的重 要化学反应, 该类反应具有反应条件温和、转化率高、 选择性好等优点, 因而在合成液晶化合物、医药、农药 和有机合成中间体等领域有着广泛应用. 其中不同结构 的催化剂也逐渐被开发出来, 包括经典的钯-膦配体催 化体系及随后发展的钯-氮杂环卡宾 $(\mathrm{NHC})$ 类催化体系.

$\mathrm{N}$-杂环卡宾配体是近年来被广泛研究报道的一类 配体. 特别是其可以与金属很好络合并参与众多化学反 应的特性使得科学家们对其进行广泛而深入的研究. 早 在 1968 年, Ofele ${ }^{[1]}$ 和 Wanzlick 等 ${ }^{[2]}$ 就报道了 $\mathrm{N}$-杂环卡 宾金属络合物的结构和制备方法. 但在随后的二十多年 里, 对于 N-杂环卡宾化学的研究进展缓慢. 直到 1991 年, Arduengo 等 ${ }^{[3]}$ 报道了一种游离态的且在空气中可以
稳定存在的卡宾 1 , 才引起了科学界的广泛关注. 随后 各种不同结构的 N-杂环卡宾逐步发展起来(Scheme 1).

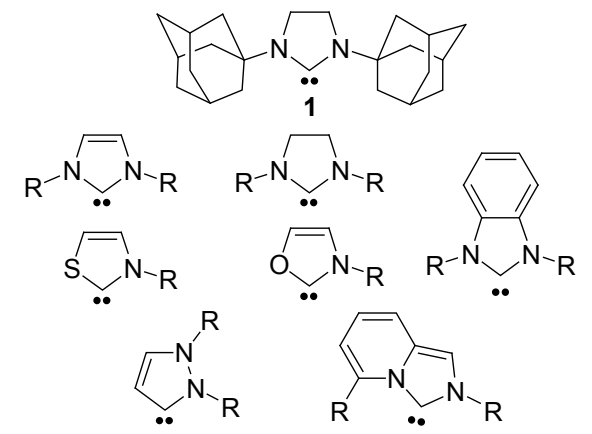

Scheme 1

\footnotetext{
*E-mail: caoyc@srici.cn

Received August 26, 2013; revised October 28, 2013; published online November 14, 2013.

Project supported by the Shanghai Municipal Science and Technology Commission (Nos. 12NM0504500, 13XD1421700).

上海市科学技术委员会(Nos. 12NM0504500 和 13XD1421700)资助项目.
} 
$\mathrm{N}$-杂环卡宾配体具有以下几种优良特性: (1)是一种 良好的 $\sigma$-供电子体, 可与多种金属配位形成比较牢固的 $\mathrm{C}-\mathrm{M}$ 键, 因此在催化反应中不需要加入过量的配体以 防止配体解离, 并可加速反应中底物与钯活性中心的氧 化加成; (2)配体本身具有共轭结构, 稳定性良好. 首先, $\mathrm{N}$ 杂原子具有的吸电子性质可以稳定卡宾 $\mathrm{C}$ 原子的孤对 电子; 其次, $\mathrm{N}$ 原子 $\mathrm{P}$ 轨道上的孤对电子还可以与卡宾 $\mathrm{C}$ 上的一对电子发生共轭作用从而稳定卡宾结构; 另外与 氮原子相连的杂环上的 $\mathrm{C}=\mathrm{C}$ 参与共轭, 也增加了整个 体系的稳定性; (3)结构多元化, 易于修饰, 通过改变 N 原子上所连基团, 就能调整配体空间结构和电子效应, 位阻效应明显; (4)制备简单、使用方便、毒性小、稳定 性高, 可以广泛应用于多种有机金属催化反应中; (5)对 空气、水、热具有良好的稳定性.

$\mathrm{NHC}$ 配体可与多种金属配位形成 $\mathrm{N}$ 杂环卡宾金属 络合物, 如 $\mathrm{Ag}, \mathrm{Cu}, \mathrm{Ru}, \mathrm{Os}, \mathrm{Cr}, \mathrm{Mo}, \mathrm{Ni}, \mathrm{Fe}, \mathrm{Pd}$, 例如著名 的 Grubbs 二代催化剂 ${ }^{[4]}$. 本文探讨了近年来, 特别是 2010 年以来新发现的不同结构 NHC 配体与 Pd 络合形 成的 Pd-NHC 型催化剂在多种交叉偶联反应中的应用. 除了 Pd-NHC 催化剂运用较多的 Suzuki, Heck 等交叉偶 联反应外，还包括该类催化剂在 Kumada, Hiyama, Buchwald, Negishi 等反应中的应用.

$\mathrm{N}$ 杂环卡宾配体主体结构具有多种类型的结构, 例 如最常见的五元咪唑环, 以及近年来出现较多的苯并咪 唑环, 还有六元 $\mathrm{N}$ 杂环结构配体, 以及其他类型的 $\mathrm{N}$ 杂 环结构等. 本文将根据 NHC 配体结构的不同, 在李争 宁 ${ }^{[5]}$, Nolan ${ }^{[6]}$, Haque ${ }^{[7]}$, Huynh ${ }^{[8]}$ 等相关综述的基础之上. 着重对 2010 年以后的 Pd-NHC 催化剂催化的多种交叉 偶联反应进行综述(除少数一些经典的催化剂体系外, 多数催化体系是在 2010 2013 年之间报道的).

\section{1 单五元咪唑环结构的 Pd-NHC 催化剂}

这类型结构的催化剂是目前报道最多, 也是最常见 的一类催化体系, 其在 Suzuki 交叉偶联反应中的应用最 早由 Herrmann 等报道. 他们所制备的具有五元环咪唑 结构的 Pd-NHC 具有里程碑的意义. 上述催化剂 2 催化 活泼的溴代底物效果非常好(Scheme 2). 次年, 该小组 ${ }^{[9]}$ 通过改变 $\mathrm{N}$ 原子上的连接基团得到了一种大位阻催化 剂 3. 运用此催化剂催化苯嗍酸与卤代芳烃的偶联时, 无论非卡宾配体是 $\mathrm{PPh}_{3}$ 还是 $\mathrm{PCy}_{3}$, 对于催化活泼的或 者是不活泼的溴代芳烃如对澳苯乙酮、对澳苯甲醚等, 反应 12 14 h 均能达到 $99 \%$ 的产率; 而催化相对惰性的 氯代芳烃时, 当 $\mathrm{R}=\mathrm{PCy}_{3}$ 时, 催化活泼的对氯苯乙酮, 反应 $13 \mathrm{~h}$, 收率可达 $90 \%$, 催化不活泼的对氯苯甲醚, 更换 $\mathrm{Cs}_{2} \mathrm{CO}_{3}$ 作碱, 反应 $32 \mathrm{~h}$, 收率则为 $69 \%$, 当 $\mathrm{R}=$
$\mathrm{PPh}_{3}$ 时，效果不如 $\mathrm{R}=\mathrm{PCy}_{3}$ 显著. 此后，基于五元环咪 唑结构的 NHC 配体有了更大的发展，包括 $\mathrm{N}$ 原子上取 代基团的进一步丰富以及全新类型非卡宾配体的开发.
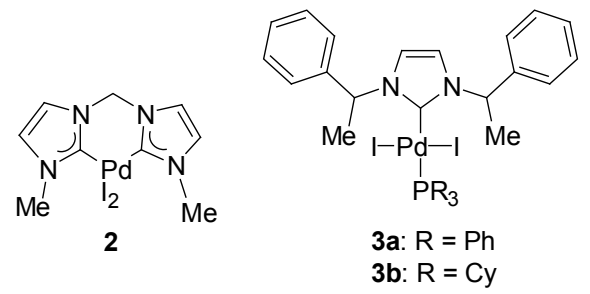

Scheme 2

对 Pd-NHC 催化体系作出重要贡献的 Nolan 课题 组 ${ }^{[10]}$ 在 1999 年合成报道了一种 1,3-双(2,4,6-三甲基苯 基)咪唑盐结构的化合物 4 与 $\mathrm{Pd}_{2}(\mathrm{dba})_{3}$ 结合使用来催化 对氯甲苯和苯硼酸偶联. 当 $\mathrm{Pd}_{2}(\mathrm{dba})_{3}$ 用量为 $1.5 \mathrm{~mol} \%$, 配体 4 用量为 $3.0 \mathrm{~mol} \%, \mathrm{Cs}_{2} \mathrm{CO}_{3}$ 作碱情况下, $80^{\circ} \mathrm{C}$ 反应 $1.5 \mathrm{~h}$ 收率可达 $96 \%$. 并且催化与大位阻的芳基硼酸偶 联, 同样条件下收率仍可达 $80 \%$ 以上. 而后, Nolan 等 ${ }^{[1]}$ 运用典型的五元咪唑环 NHC 配体与钯络合, 并采用烯 丙基结构的化合物作为非卡宾配体, 形成颇具特色的催 化剂(如 Scheme 3 所示)并且具有非常好的催化效果, 甚 至对于非活化的氯代芳烃的 Suzuki 偶联效果也很理想, 催化剂用量甚至可以低至 $0.005 \mathrm{~mol} \%$.
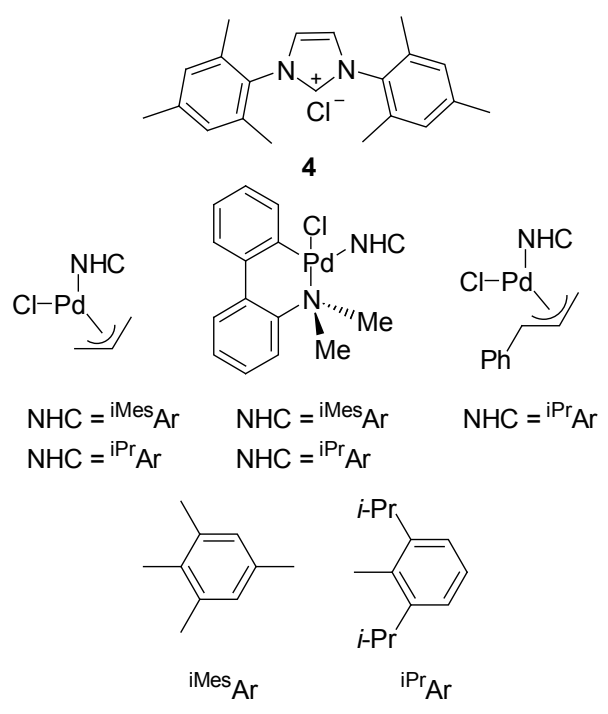

Scheme 3

Dorta 课题组 ${ }^{[12]}$ 受 Nolan 等工作的影响，同样采用 肉桂基作为非卡宾配体，但对五元环咪唑 $\mathrm{N}$ 原子上的取 代基做了极大改变. 他们在 $\mathrm{N}$ 原子上引入 2 位或是 2,7 位连接有环辛基(cyclooctyl groups, 简写为 Cyoct)的荎 环, 合成了催化剂 8, 并与 Nolan 和 Organ 等前报道的经 典催化剂 9, 10, 12e 进行比较. 室温下催化 2,4,6-三甲基 氯苯和 2,6-二甲基苯硼酸的偶联形成大位阻的邻位四取 
代联苯化合物 7 (Eq. 1), 结果显示 8 的催化反应收率可 达 90\%，结果优于 Nolan 和 Organ 等之前报道的 (SIPr)Pd(cin)Cl, (IPr)Pd(cin)Cl 和 Pd-PEPPSI-IPent 催化 剂体系; 计算化学显示, 8 具有更大的位阻. 随后, 以 $\mathrm{KO} t$ - $\mathrm{Bu}$ 作碱, 甲苯作溶剂, 室温下催化剂 8 即可非常高 效的催化多种类型大位阻的溴代以及氯代芳烃与芳基 嗍酸的偶联.
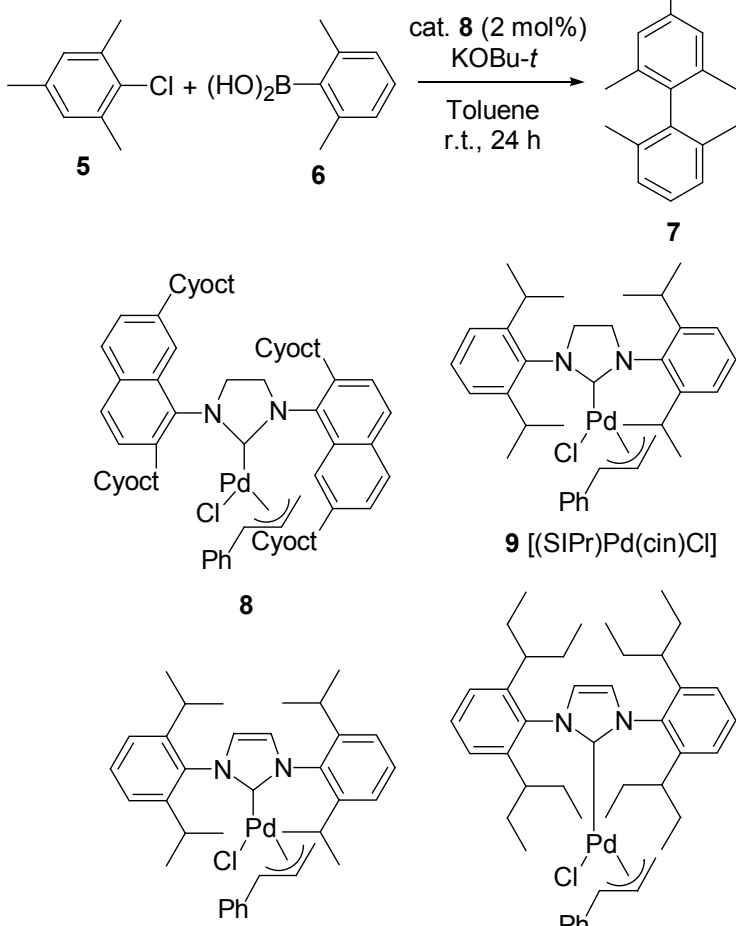

$10[(\operatorname{Pr}) \operatorname{Pd}(\operatorname{cin}) \mathrm{Cl}]$
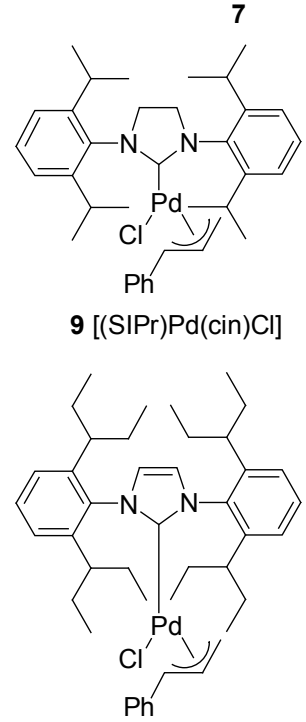

12e [Pd-PEPPSI-IPent]

在 Nolan 小组的工作基础上, Organ 小组也对五元 环咪唑类结构的 NHC 配体做了进一步的衍生, 通过对 咪唑环上 $\mathrm{N}$ 原子所连基团的改变, 发展出一些新型的大 位阻 Pd-NHC 催化剂(Eq. 2). 2006 年, Organ 等 ${ }^{[13]}$ 克服了 Pd-NHC 型催化剂合成条件严格, 收率不高的缺陷, 在 敞开体系中加热 $\mathrm{NHC} \cdot \mathrm{HCl}$ 的盐 $\mathbf{1 1}$ 与 $\mathrm{PdCl}_{2}$ 和 3 -氯吡啶 反应就可高效地以 $>90 \%$ 的收率得到目标催化剂 $\mathbf{1 2}$. 在 这里, 他们小组首次报道了利用吡啶作为非卡宾配体配 合 NHC 与钯络合形成催化剂, 称其为 PEPPSI 型催化剂 (Pyridine Enhanced Precatalyst Preparation Stabilization and Initiation). 他们将该催化剂用于氯代芳烃的偶联, 结果也非常令人满意. 以对氯苯甲醚为例, 采用 $\mathrm{KO} t-\mathrm{Bu}$ 作碱, $i-\mathrm{PrOH}$ 为溶剂, 以及 $1 \mathrm{~mol} \%$ 12a 作为催化 剂在室温下反应 $2 \mathrm{~h}$, 即可达到 $97 \%$ 的收率. 随后他们 又用更廉价的苯基三氟硼酸钾与对氯苯甲醚反应, $\mathrm{MeOH}$ 作溶剂, $\mathrm{K}_{2} \mathrm{CO}_{3}$ 作碱, 室温下反应 $24 \mathrm{~h}$ 收率为 $86 \%$, 若加热至 $60{ }^{\circ} \mathrm{C}$ 反应, 收率可升至 $90 \%$; 不仅如 此, 催化剂 12a 还可催化合成多种大位阻的联芳基化合

物(如很有应用价值的邻位四取代联芳基化合物)以及联 杂环芳基化合物等.
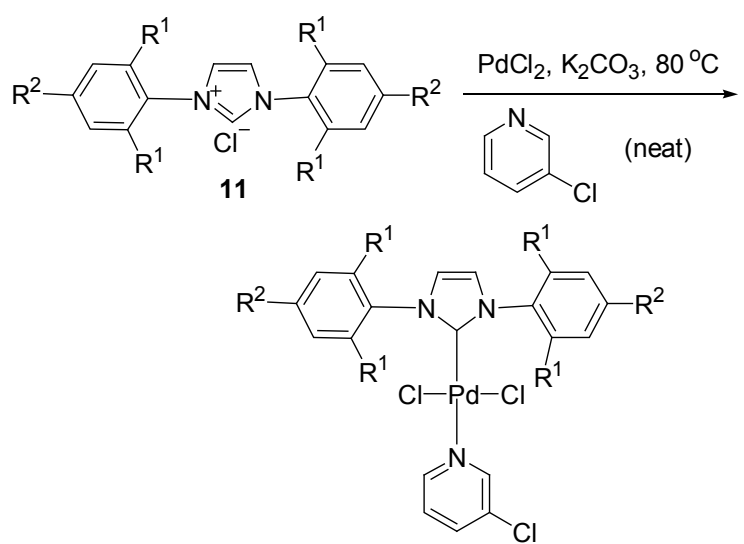

$$
\begin{aligned}
& \text { 12a: } \mathrm{R}^{1}=i-\operatorname{Pr}, \mathrm{R}^{2}=\mathrm{H}, \text { Pd-PEPPSI-IPr } \\
& \text { 12b: } R^{1}=\text { Et, } R^{2}=H, \text { Pd-PEPPSI-IEt } \\
& \text { 12c: } R^{1,2}=\text { Me, Pd-PEPPSI-IMes } \\
& \text { 12d: } \mathrm{R}^{1}=i-\mathrm{Bu}, \mathrm{R}^{2}=\mathrm{H}, \text { Pd-PEPPSI-IBu } \\
& \text { 12e: } \mathrm{R}^{1}=i \text {-Pent, } \mathrm{R}^{2}=\mathrm{H} \text {, Pd-PEPPSI-IPent } \\
& \text { 12f: } R^{1}=c \text {-Pent, } R^{2}=H \text {, Pd-PEPPSI-CPent }
\end{aligned}
$$

Martin 等 ${ }^{[14]}$ 利用上述已商用的 Pd-PEPPSI-IPr 型催 化剂 12a 催化邻位双取代碘代芳烃与芳基嗍酸的插湠偶 联，得到联芳基酮类化合物 14 (Scheme 4). 反应于 101 $\mathrm{kPa} \mathrm{CO}$ 气压, 氯苯为溶剂, $\mathrm{Cs}_{2} \mathrm{CO}_{3}$ 作碱, $80{ }^{\circ} \mathrm{C}$ 反应 24 $\mathrm{h}$, 并与在 CO $0.41 \mathrm{MPa}$ 压力, 二氧六环作溶剂, $140{ }^{\circ} \mathrm{C}$ 环境的反应对比，结果显示前者反应收率(95\%)高于后 者 $(82 \%)$, 并且该催化反应体系适用于多种有机硼试剂 和邻位双取代碘代芳烃的羰基化偶联; 而后他们又将此 催化体系运用在邻位双取代碘代芳烃和有机锌试剂的 Negishi 偶联反应中, 亦表现出了不错的催化活性.

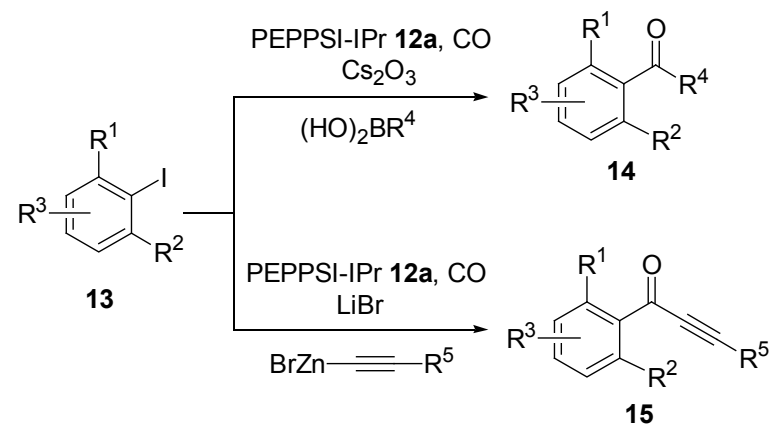

Scheme 4

Organ 等 ${ }^{[15]}$ 发现他们合成的这种类型催化剂同样在 Buchwald 偶联反应中表现出了极佳的催化性能. 前期 探索实验显示, 碱和溶剂的选择对催化剂活性影响很 大，最终确定了 $\mathrm{KO} t$ - $\mathrm{Bu}, \mathrm{DME}$ 反应体系. 他们发现在室 温下, 催化剂 12a 即可高效的催化氯代芳烃与有机胺化 合物的偶联，底物可以是一些大位阻的氯代芳烃和有机 胺类，对于杂环芳烃同样适用. 研究发现催化体系可以 
接受溶剂极性的变化, 并且对于一些对强碱 $\mathrm{KO} t-\mathrm{Bu}$ 比 较敏感的底物, 碱可以更换为一些弱碱诸如 $\mathrm{Cs}_{2} \mathrm{CO}_{3}$ 参 与反应, 对反应收率影响不大.

2010 年, Organ 等 ${ }^{[16]}$ 又运用它们合成报道的 PdPEPPSI 型催化剂应用在卤代芳烃和有机锌试剂的 Negishi 偶联反应中. 结果发现催化剂 12a (Pd-PEPPSIIPr), 12e (Pd-PEPPSI-IPent)表现出来最佳的催化活性, 并且 12e 对大位阻底物表现尤其突出. 同时在试验中他 们发现 $\mathrm{LiBr}$ 作为添加剂的加入以及在反应用量的多少 中非常关键, 他们认为 $\mathrm{LiBr}$ 参与形成活性转金属化物 种，而转金属化这一步骤是该反应的速控步骤.

2012 年, Nolan 课题组 ${ }^{[17]}$ 在 Organ 等合成的 PdPEPPSI 型催化剂基础上, 通过改变 $\mathrm{N}$ 原子所连苯环上 的基团结构合成了催化剂 $\mathbf{1 6}$ (Scheme 5). 16 可在用量低 至 $0.5 \mathrm{~mol} \%$ 时, 室温下高效催化多种类型氯代芳烃(包 括杂环芳烃)与一系列有机胺类化合物的 Buchwald 偶 联, 收率在 74\% 96\%。

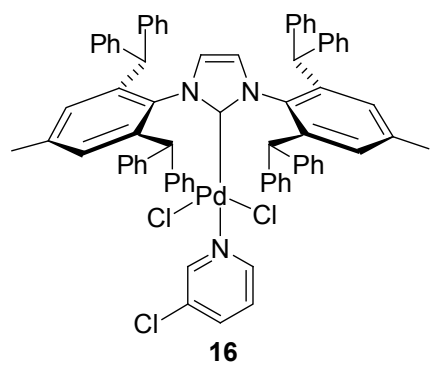

Scheme 5

Chen 等 ${ }^{[18]}$ 通过修饰咪唑环上 $\mathrm{N}$ 原子所连基团引入 嘧啶结构, 通过 $\mathrm{C}, \mathrm{N}$ 原子的双配位形成催化剂 17 (Scheme 6). 该催化剂展现出了对于各种类型的澳代芳 烃以及活化的氯代芳烃非常高的催化活性, $1 \mathrm{~mol} \%$ 在很 短时间内 $(0.5 \mathrm{~h} \sim 2 \mathrm{~h})$ 就能高效催化其与苯硼酸的 Suzuki 偶联, 反应收率多在 $90 \%$ 以上. 而后, 他们将催 化剂 17 用于卤代芳烃与苯基三甲氧基硅烷的 Hiyama 偶联中, 结果显示对于溴代芳烃以及一些活化的氯代芳 烃, 17 的表现令人满意, 但对于一些未活化的氯代芳烃, 催化性能稍差.

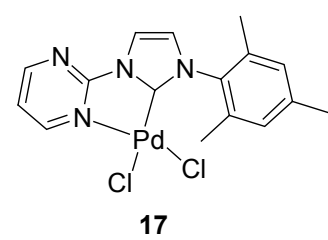

Scheme 6

$\mathrm{Lu}$ 课题组 ${ }^{[19]}$ 同样采用五元环咪唑结构的 NHC 配 体, 引入甲基咪唑作为非卡宾配体, 成功开发出 NHC-
Pd-methylimidazole 型催化剂 18 (Scheme 7). 在室温下, 仅使用 $1 \mathrm{~mol} \%$ 催化剂就可催化氯代芳烃与芳基硼酸的 偶联. 使用 $V\left(\mathrm{H}_{2} \mathrm{O}\right): V(\mathrm{THF})=2: 1$ 的混合溶剂配合水 合磷酸钾作碱，反应 $24 \mathrm{~h}$ 就可以 $85 \% \sim 99 \%$ 的收率得到 活化或未活化氯代芳烃与芳基硼酸的偶联产物。该催化 剂亦可催化大位阻氯代芳烃与大位阻芳基硼酸的偶联, 收率也很高.

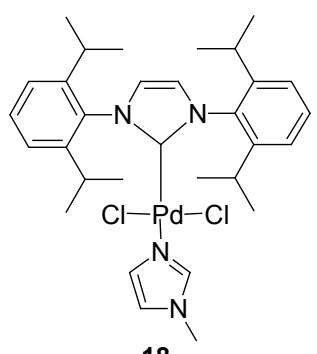

18

\section{Scheme 7}

$\mathrm{Lu}$ 等 ${ }^{[20]}$ 后又将催化剂 $\mathbf{1 8}$ 应用于 Hiyama 偶联反应 中, $1 \mathrm{~mol} \%$ 催化剂用量催化对氯苯乙酮与苯基三甲氧基 硅烷的偶联反应, 经过实验确定了反应条件, 并且发现 $\mathrm{TBAF} \cdot 3 \mathrm{H}_{2} \mathrm{O}$ 作为活化剂为反应所必须, 反应收率较高 可至 $85 \%$; 随后扩展底物范围至未活化, 大位阻以及一 些杂环氯代芳烃, 反应收率均较理想. 不仅如此, 他们 还发现该催化剂还可运用于在水相中催化多种类型芳 基硼酸与芳基羧酸䣶的偶联 ${ }^{[21]}$ ，得到芳基酮化合物 21 (Eq. 3), 反应条件温和、方便简单，收率也非常理想. 作 者认为除了应用于常见的偶联反应体系, Pd-NHC 催化 剂催化合成联芳基酮化合物的可以为有机合成提供新 的思路.

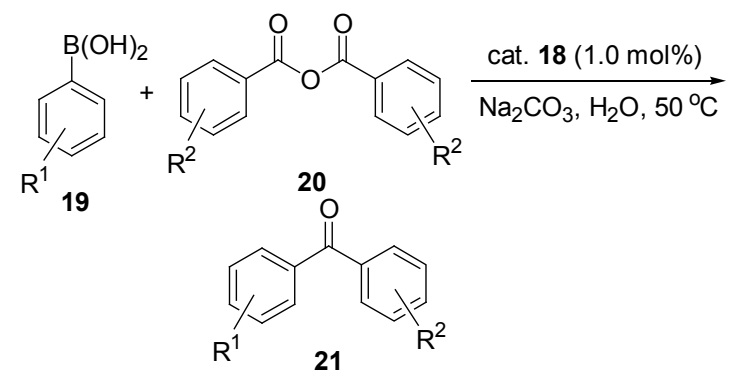

Huynh 等 ${ }^{[22]}$ 在 Herrmann 小组 ${ }^{[23]}$ 曾报道催化剂基础 上，将 $\mathrm{N}$ 原子所连基才变更为大位阻 2,4,6-三甲基苯基 基团，并经金属交换得到了另外两种催化剂 22 和 23 (Eq. 4), 在合成催化剂 23 时, 意外的得到了一种双核 Ag-Pd-NHC 催化剂 24. 1 mol\%催化剂 22 和 23 在催化溴 代芳烃与正丁基丙烯酸酯的 Heck 反应时，比较非卡宾 配体对催化剂活性的影响, 其中 23b 表现最好; 当底物 变化为氯代芳烃时, 加入 1.5 equiv. $\left[\mathrm{N}\left(n-\mathrm{C}_{4} \mathrm{H}_{9}\right)_{4}\right] \mathrm{Br}$ 作为 稳定剂时，催化剂 22, 23b 表现出了一定的活性. 

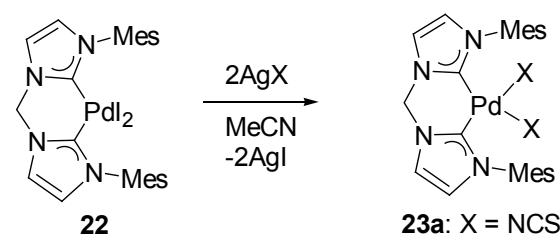

23a: $X=$ NCS

23b: $\mathrm{X}=\mathrm{CF}_{3} \mathrm{COO}$
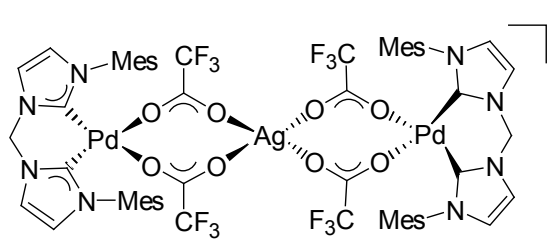

24

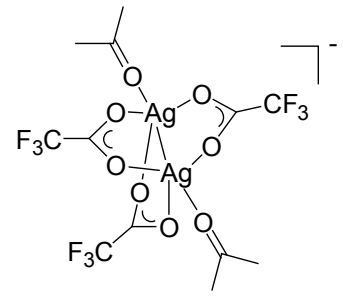

Jin 等 ${ }^{[24]}$ 合成报道了一种环戊二烯和 NHC 配体与 Pd 配位形成的催化剂 25 (Scheme 8), 由于催化剂结构 中环戊二烯环在还原消除这一步骤中的高度敏感性, 因 此对含有环戊二烯配体的催化剂研究并不深入. Jin 小组 所合成的催化剂成功避免了环戌二烯的不良影响，显示 出对氯代芳烃偶联反应的高效性能. 他们以对甲基苯硼 酸与对氯苯甲醚的偶联反应为例, 催化剂使用量为 1 mol\%, 室温下 25d 催化效率最高, 反应收率可达 100\%, 于是他们扩展底物范围, 发现该催化剂对一系列活化或 未活化的氯代芳烃以及一些大位阻的硼酸均表现出了 很好的催化性能; 非常有意思的是, 他们将此催化剂用 于硼酸的自偶联反应中, 发现同样在室温下, 便可催化 无大位阻嗍酸的自偶联反应，收率也非常高( $>90 \%)$. 当意识到催化剂 25 表现出的催化性能如此优秀时, Jin 等又将催化剂应用在构建 $\mathrm{C}-\mathrm{N}$ 键的 Buchwald 胺化反 应. 在 DME, $\mathrm{NaO} t-\mathrm{Bu}$ 环境中, $1 \mathrm{~mol} \%$ 催化剂在室温下 就可催化多种类型氯代芳烃与一级或二级芳胺的偶联, 反应收率多在 $80 \%$ 以上. 作者认为该催化剂在催化 Suzuki 以及 Buchwald 反应的高效活性应当归结于环戊 二烯基团在反应中易与 $\mathrm{Pd}$ 脱离, 从而更易形成 NHC-Pd(0)催化活性中心. 他们后又将该催化剂用于催 化对氯苯甲醚与苯基格式试剂的 Kumada 偶联反应 ${ }^{[25]}$ 时, 25a 25d 室温下均可催化反应发生, 其中位阻最小 的催化剂 25a, 25c 的活性远高于另外两种大位阻的催化 剂, 这与我们通常认为的大位阻则高活性催化体系相 反; 其后 $1 \mathrm{~mol} \%$ 催化剂 $25 \mathrm{c}$ 用于多种类型氯代芳烃的偶 联时, 表现出了不俗的催化活性.

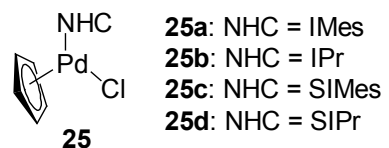

\section{Scheme 8}

2011 年, Hashmi 等 ${ }^{[26]}$ 对五元咪唑环 $\mathrm{N}$ 原子上的连 接基团进行了调整, 引入多元大环烷基作为其中一个取
代基，并探索取代基的空间位阻效应对催化剂 26 活性 的影响. 他们发现五元咪唑环上取代基的位阻对催化剂 的活性影响很大，其中连有环十二烷和 2,6-二异丙基苯 基团构建的催化剂 26a 活性最好, 在室温下就可高效催 化氯苯与 2,5-二甲基苯嗍酸的偶联，反应 $0.5 \mathrm{~h}$, 收率可 达 97\% (Eq. 5).

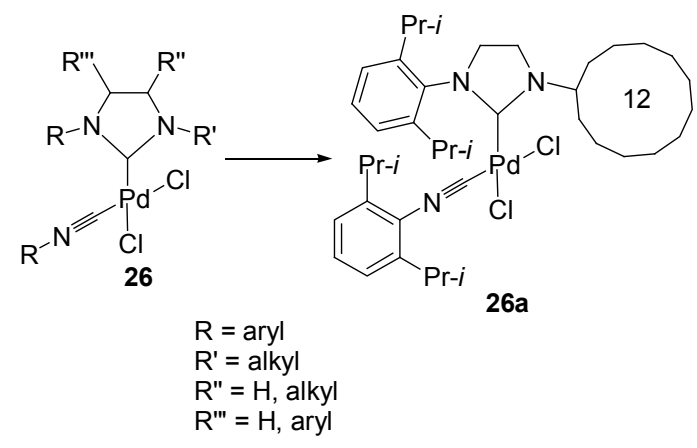

Saito 等 ${ }^{[27]}$ 合成报道了一种刚性联荎基团桥连的双 核 Pd-NHC 催化剂 27 (Scheme 9), 该催化剂在催化溴代 芳烃与丙烯酸丁酯的 Heck 反应时, $\mathrm{N}$ 原子所连基团的变 化对催化剂性能影响不大, 该系列催化剂在催化活化的 溴代芳烃时，表现出不错的催化活性，但在催化未活化 的溴代芳烃时，反应收率不高.

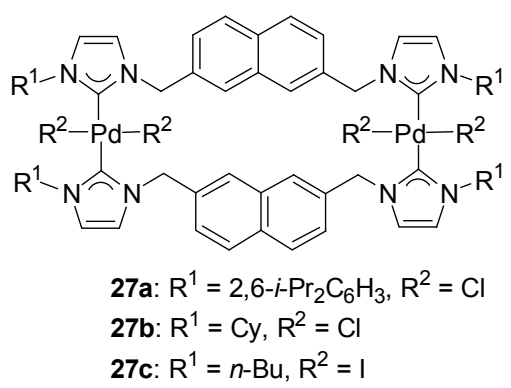

Scheme 9

2012 年, Cai 等 ${ }^{[28]}$ 报道了一种基于五元咪唑结构的 
催化剂 28 (Scheme 10), 但与传统的催化剂不同, 该催 化剂首次在五元咪唑环的 $\mathrm{N}$ 原子上引入全氟取代的 $\mathrm{C}_{6} \mathrm{~F}_{13}$ 基团形成氟化的催化剂. 由于大多数的氟代催化 剂在有机溶剂中相对难溶, 因此作者采用对此类催化剂 具有较好溶解性的“氟两相”一全氟环己烷 $V\left(\mathrm{C}_{6} \mathrm{~F}_{12}\right)$ : $V(\mathrm{EtOH})=1: 1$ 的溶剂体系, 顺利地解决了催化剂的溶 解度问题. 另外, 全氟取代的溶剂与有机溶剂之间相互 溶解性与温度密切相关, 温度高时可以完全互溶, 而温 度低时则呈两相. 在反应中, 温度控制在 $80{ }^{\circ} \mathrm{C}$, 使用 $0.1 \mathrm{~mol} \%$ 催化剂, $\mathrm{KOH}$ 作碱, 可以高效催化溴代芳烃的 偶联. 而当反应结束后, 冷却, 原本在高温下相溶的两 种溶剂变得互不相溶, 含氟的催化剂 28 就可与有机相 中的产物很好的分离, 可以方便实现催化剂的再次利 用. 他们在此催化体系中反复使用了催化剂 3 次, 活性 仍可保持最初的催化效率.

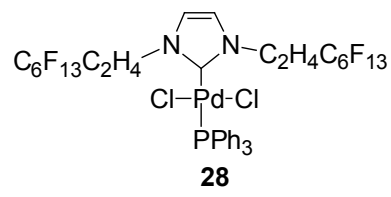

\section{Scheme 10}

Plenio 小组 ${ }^{[29]}$ 用类似的水溶性配体, 引入肉桂基作 为非卡宾配体合成了催化剂 $\mathbf{2 9}$, 催化剂 29 实现了在低 催化剂用量条件下 $(0.1 \mathrm{~mol} \%)$, 在混合溶剂 $V\left(\mathrm{H}_{2} \mathrm{O}\right)$ : $V(n$-butanol $)=1: 1$ 体系中, 催化未活化氯代芳烃及杂 环芳烃与芳基硼酸的 Suzuki 偶联. 反应收率大多在 $90 \%$ 以上, 多数甚至可达 $99 \%$. 不仅如此, 该催化剂在催化 卤代芳烃与末端炔烃的 Sonogashira 反应时(Eq. 6), 同样 表现出极高的催化活性.

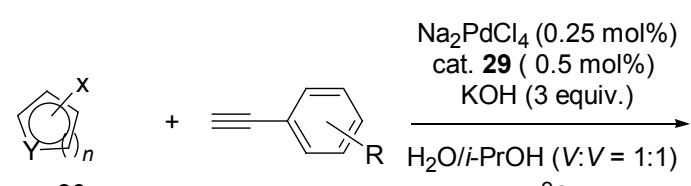

30

31

$90 \sim 95{ }^{\circ} \mathrm{C}, 12 \mathrm{~h}$

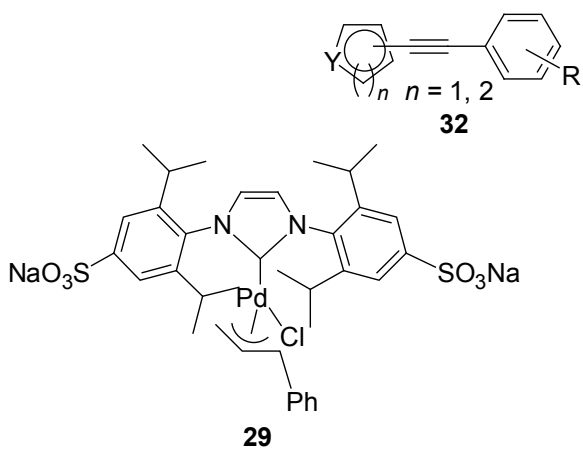

(6)

Cazin 等 ${ }^{[30]}$ 合成报道了一种二聚的 Pd-NHC 催化剂 33 催化氯代芳烃与芳基格氏试剂的 Kumada 偶联(Eq. 7),
反应在 $0.2 \sim 0.45 \mathrm{~mol} \%$ 催化剂用量下, $\mathrm{THF}$ 为溶剂, 60 ${ }^{\circ} \mathrm{C}$ 下反应，反应结果显示催化剂 33 对官能团有很好的 耐受性，可以高效催化一系列活化或是未活化氯代芳烃 以及一些杂环芳烃，同样对于大位阻的底物也有着很好 的催化性能.

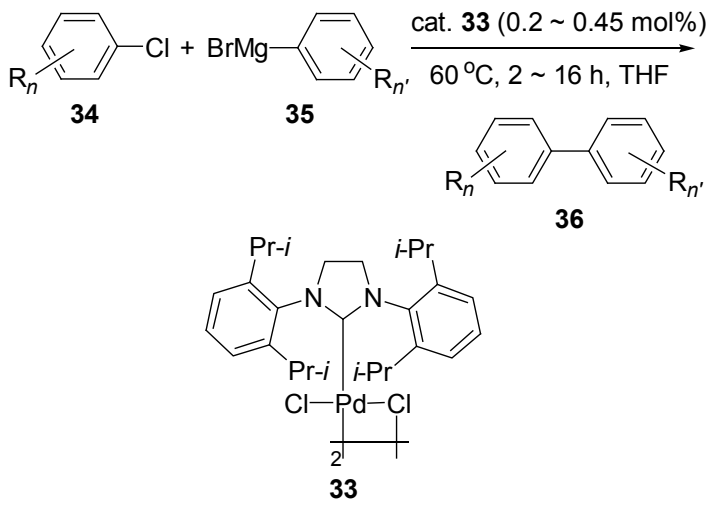

2012 年, $\mathrm{Lu}$ 等 ${ }^{[31]}$ 在咪唑环 $\mathrm{N}$ 原子上引入吡咯烷结 构进一步合成了一种双核 Pd-NHC 催化剂 37 (Scheme 11). $1 \mathrm{~mol} \%$ 该催化剂在纯水中能很好的催化碘代及活 化的溴代芳烃与丙烯酸的 Heck 反应.

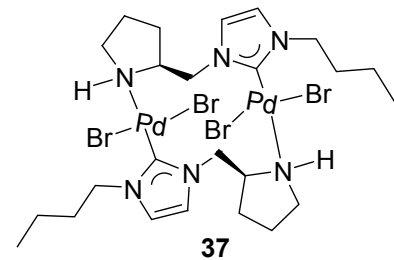

Scheme 11

最近, Nolan 等 ${ }^{[32]}$ 又报道了一种能在无溶剂环境中 催化 Buchwald 偶联反应的 Pd-NHC 催化剂 38 (Scheme 12). $1 \mathrm{~mol} \%$ 该催化剂在 $\mathrm{KO} t-\mathrm{Am}$ 作碱，室温下反应很短 时间(5 min $2 \mathrm{~h}$ )便可极其高效催化多种类型氯代芳烃 与大位阻有机胺类的 Buchwald 偶联反应, 收率多在 $90 \%$ 以上. 有意思的是，当 DME 参与作溶剂时，该反应 却不能发生.

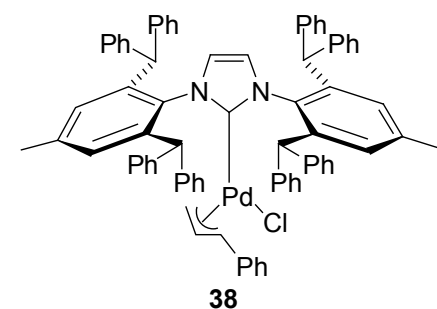

Scheme 12

Yus 等 ${ }^{[33]}$ 利用咪唑盐 $\mathrm{NHC} \cdot \mathrm{HCl}$ 与 $\mathrm{Pd}(\mathrm{OAc})_{2}$ 原位生 成的催化剂 39 参与 Hiyama 偶联反应中, 该催化体系的 特点是无需氟活化剂的参与, 且 $\mathrm{Pd}(\mathrm{OAc})_{2} / \mathrm{NHC} \cdot \mathrm{HCl}$ 的 
物质的量比对反应收率的影响大(Scheme 13). 催化剂在 $50 \% \mathrm{NaOH}$ 水溶液中, $120{ }^{\circ} \mathrm{C}$ 微波条件下反应 $30 \mathrm{~min}$ 催 化对溴苯甲醚与苯基三甲氧基硅烷的偶联, 结果显示当 $\mathrm{Pd}(\mathrm{OAc})_{2} / \mathrm{NHC} \cdot \mathrm{HCl}$ 的物质的量比为 $1: 5$ 时, 反应收率 最高可至 $95 \%$. 当催化对氯苯甲醚的偶联时, 1 equiv. $\mathrm{TBAB}$ 的加入为反应所必须, 同样当 $\mathrm{Pd}(\mathrm{OAc})_{2} / \mathrm{NHC}$ $\mathrm{HCl}$ 的物质的量比为 1:5 时, 反应收率最高可至 $92 \%$. 该催化体系对多种结构类型的溴代或是氯代芳烃同样 适用.<smiles>OC(CN1C=CN(Cc2ccccc2)C1)c1ccccc1</smiles>

Scheme 13

\section{2 双五元咪唑环结构的 Pd-NHC 催化剂}

双五元咪唑环结构的 Pd-NHC 催化剂最早见于 Herrmann 小组 ${ }^{[34]}$ 的报道. 该小组在发展了单五元咪唑 环结构的 Pd-NHC 催化剂的基础上, 又开发出具有对称 结构, 四金刚烷基取代的双五元环咪唑结构的大位阻催 化剂 40 (Scheme 14), 该催化剂在 1,4-二氧六环作溶剂, $\mathrm{CsF}$ 作碱条件下，使用 $3 \mathrm{~mol} \%$ 催化剂用量就可在常温下 催化一系列活化以及非活化氯代芳烃与苯嗍酸的偶联, 效果非常好.

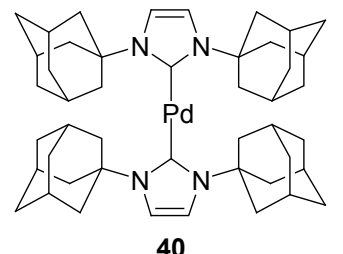

Scheme 14

2010 年, Liu 等 ${ }^{[35]}$ 合成了一系列由饱和五元咪唑环、 不饱和五元咪唑环以及两种咪唑环混合作为配体的双 NHC 配位的 Pd-NHC 催化剂 41 44 (Scheme 15). 作者

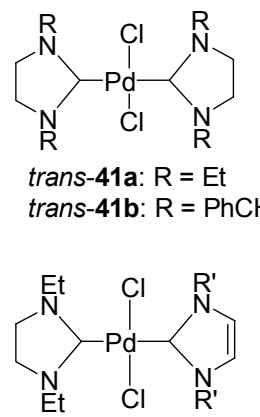

trans-43a: $\mathrm{R}^{\prime}=\mathrm{Et}$ trans-43b: $\mathrm{R}^{\prime}=2,6-i-\mathrm{Pr}_{2} \mathrm{C}_{6} \mathrm{H}_{3}$
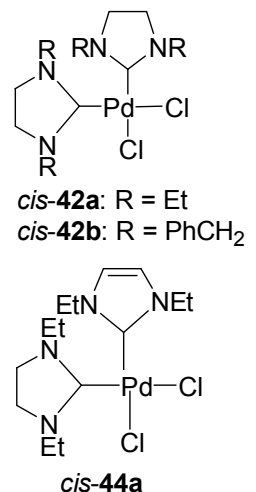

Scheme 15
比较 $\mathrm{N}$ 原子上所连基团对催化剂性能的影响. 结果显示 在该催化剂体系中拥有更强 $\sigma$ 供电子能力的不饱和 $\mathrm{NHC}$ 配体在催化性能上却弱于饱和 NHC 配体，同时相 同 NHC 配体的催化剂优于采用混合 NHC 配体的催化 剂。该反应在回流温度下，催化剂使用量仅为 0.002 $\mathrm{mol} \%, \mathrm{~K}_{3} \mathrm{PO}_{4}$ 作碱，水相中可催化对氯苯乙酮与苯硣酸 的偶联反应, 使用催化剂 $41 \mathrm{a}$ (反应加入 $t-\mathrm{Bu}_{3} \mathrm{P}$ )反应收 率最高( $>99 \%$ ), 并且 42a 也表现出了优良的性能. 在此 催化体系中, 数据显示有着大位阻的 Pd-NHC 催化剂在 催化性能上的表现却不如小位阻催化剂.

Whittlesey 等 ${ }^{[36]}$ 报道了一种全新的、具有双五元咪 唑环配位的三核三角架结构的 Pd-NHC 催化剂 45. 这是 为数不多的多核 Pd-NHC 催化剂的例子. 该类型催化剂 催化溴代以及碘代芳烃时，使用 $0.83 \mathrm{~mol} \%$ 催化剂， $\mathrm{Cs}_{2} \mathrm{CO}_{3}$ 作碱, dioxane 作溶剂, 控制反应温度在 $120{ }^{\circ} \mathrm{C}$, 催化效果良好，但是该反应体系对氯代芳烃底物并不适 用. 并且他们还尝试了催化剂 45 在 Sonagashira 以及 Buchwald 反应中的运用(Eq. 8). 2011 年, Liu 等 ${ }^{[37]}$ 也合成 了一种新颖的 1,8-二氮杂萗桥连的双 NHC 配位的催化 剂，二氮杂荎本身的 $\mathrm{N}$ 原子可以参与配位. 该催化剂可 以很好地催化溴代芳烃底物的偶联; 同时对溴代以及碘 代芳烃和溴化苯基镁的 Kumada 偶联也展现出了不错的 活性.

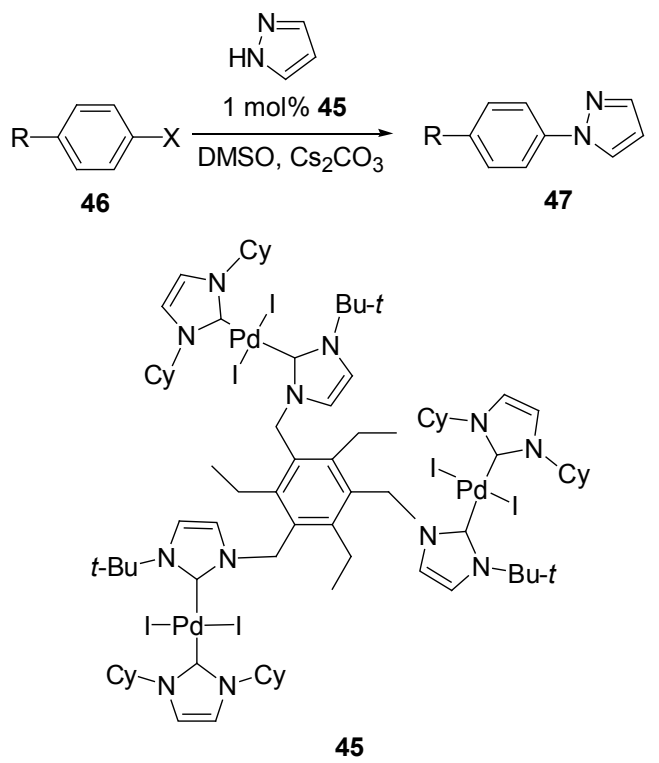

2012 年, Luo 等 ${ }^{[38]}$ 报道了五元咪唑环上 $\mathrm{N}$ 原子连有 冠醚结构的 Pd-NHC 催化剂 48 (Scheme 16), 可在较低 用量且无需气体保护的条件下参与水相溴代芳烃的 Suzuki 交叉偶联反应. 作者认为冠醚基团能有利于形成 更稳定的 $\mathrm{C}-\mathrm{Pd}$ 键. 在催化水相对溴苯甲醚和苯嗍酸的 偶联反应实验中, 发现 $\mathrm{KO} t-\mathrm{Bu}$ 是最适合该催化剂的碱, 其中 $48 \mathrm{~b}$ 展现出了更好的催化活性, 催化剂用量仅需 
$0.001 \sim 0.005 \mathrm{~mol} \%$.

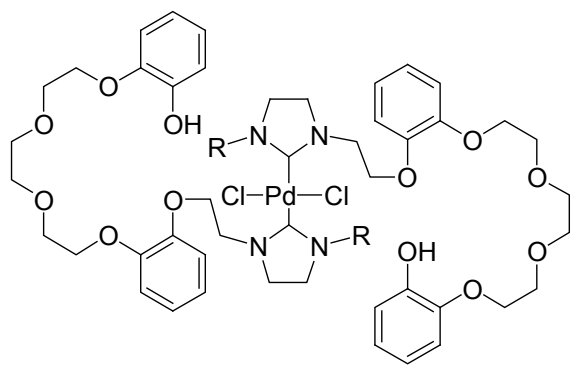

48a: $R=$ mesityl

48b: $R=2,6$-diisopropylphenyl

\section{Scheme 16}

双咪唑环配位的 Pd-NHC 催化剂中, 在两个咪唑环 之间引入桥连基团或可以调节催化剂的空间位阻效应, 或可以增加催化剂的刚性, 抑或可以引入更多配位点, 从而直接影响到该类催化剂的催化性能. 受 Steel 等 ${ }^{[39]}$ 工作的启发, SanMartin 等 ${ }^{[40]}$ 报道了用吡啶桥连的一种 双咪唑环配位 Pd-NHC 催化剂 49 (Scheme 17), 引入的 吡啶基团与两个 NHC 配体形成三配位. 同时, 他们在吡 啶的对位引入羧基, 从而使催化剂能很好的溶解在水相 中参与反应. 催化剂 49 在用量 $0.1 \mathrm{~mol} \%$ 时, 就可非常高 效催化活泼或是不活泼溴代芳烃与芳基喼酸的偶联，反 应收率几乎都在 $99 \%$ 以上. 而后他们以澳苯与苯嗍酸的 偶联为例, 将催化剂用量降至 $10^{-7} \mathrm{~mol} \%$, 发现反应收 率仍可 $>99 \%$, 反应 TON 数高达 $1 \times 10^{9}$. 另外, 该催化 剂易与产物分离, 反应结束后, 加入乙醚即可将反应产 物萃取出来, 而存在于水相中催化剂可以顺利回收并继 续使用，且催化活性几乎没有下降.

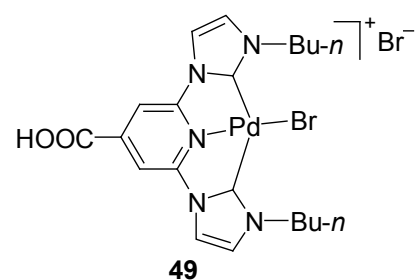

Scheme 17

2011 年, Luo 等 ${ }^{[41]}$ 又合成了一种新型的联苯基桥连 的催化剂 50 (Scheme 18). 该催化剂在敞开体系中催化 一系列活泼或是不活泼的氯代芳烃的 Suzuki 偶联时表 现出了很好的效果, 且该催化剂可通过进一步修饰环上 所连基团来调整空间位阻及电子效应.

2011 年, Hazari 等 ${ }^{[42]}$ 合成报道了由芐胺为起始物合 成的三级胺化合物桥连的 Pd-NHC 催化剂 51 (Scheme 19). 该催化剂对活泼的溴代底物催化活性不错, 但是不 能催化氯代底物与苯硼酸的偶联.

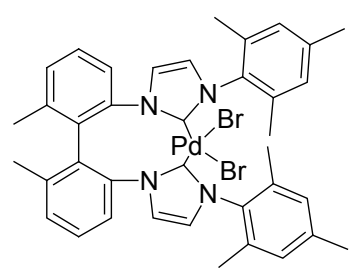

50

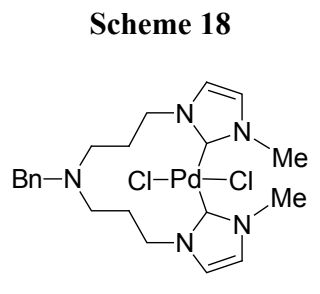

51

Scheme 19

Peris 课题组 ${ }^{[43]}$ 最近又报道了一种 NHC 配体所连基 团被磺化的 Pd-NHC 催化剂 $\mathbf{5 2}$ 于水相中参与的 Suzuki 反应，并获得了很好的 TON 数(Scheme 20). $1 \mathrm{~mol} \%$ 催化 剂催化溴代以及氯代苯乙酮催化效果很好, 反应收率非 常理想; 当降低 52 用量, 在用量 $0.001 \mathrm{~mol} \%$ 时, 催化对 溴苯乙酮收率仍可维持在 $99 \%$ 以上, 反应 TON 数 100000 , 在 $0.1 \mathrm{~mol} \%$ 用量下, 催化对氯苯乙酮表现仍非 常不错. 该类型的催化剂能很好的溶解于水中, 难溶于 大多数有机溶剂.<smiles>COCCCC1C=CN2CN3C=CC(CCCS(=O)(=O)O)C3(I)[P+](I)(I)C12</smiles>

Scheme 20

Strassner 等 ${ }^{[44]}$ 仅用亚甲基桥连合成双咪唑环配位的 Pd-NHC 催化剂 53 (Scheme 21), 并着重比较了 $\mathrm{N}$ 原子上 所连基团的不同对于催化性能的影响. 他们发现连有供 电子基团的 53b 催化效果最好, 接着是连有大位阻基团 的 53f，两者均好于带吸电子基团的 53c 和 53d. 作者认 为催化剂上的强吸电子基团会导致催化剂活性中心的 电子密度下降, 进而有可能影响到氧化加成这一决速步 骤，导致更低的反应转化率. 当使用 $1 \mathrm{~mol} \%$ 催化剂 $\mathbf{5 3 b}$ 催化对溴甲苯与苯嗍酸的偶联时, 在 $40{ }^{\circ} \mathrm{C}$ 的条件下反 应时间最短 $(2 \mathrm{~h})$, 收率达 $100 \%$; 在室温下亦可反应, $4 \mathrm{~h}$ 反应收率 $65 \%$. 当降低反应催化剂用量至 $0.5 \mathrm{~mol} \%, 40$ ${ }^{\circ} \mathrm{C}$ 反应 $6 \mathrm{~h}$ 反应收率也可达 $100 \%$. 在该反应体系中, 无 论降低催化剂用量抑或是降低反应温度都能顺利进行 反应, 而且随着反应时间的延长, 反应收率都能逐步提 高. 


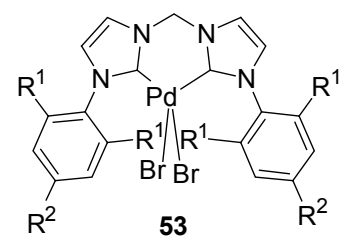

53a: $R^{1}=R^{2}=H$

53b: $R^{1}=H ; R^{2}=O M e$

53c: $R^{1}=H ; R^{2}=F$

53d: $\mathrm{R}^{1}=\mathrm{H} ; \mathrm{R}^{2}=\mathrm{NO}_{2}$

53e: $R^{1}=R^{2}=$ OMe

53f: $\mathrm{R}^{1}=i-\mathrm{Pr} ; \mathrm{R}^{2}=\mathrm{H}$

Scheme 21

\section{3 苯并咪唑环结构类型 Pd-NHC 催化剂}

NHC 配体不仅可通过修饰 N 所连原子以修饰催化 剂的催化活性, 也可改变环结构上 $\mathrm{C}$ 原子所连基团影响 $\mathrm{C}(2)$ 的 $\sigma$-供电子能力以改变催化剂的活性. 2008 年, Dötz 等 ${ }^{[45]}$ 合成了吡啶桥连双苯并咪唑 NHC 配位的 Pd-NHC 催化剂 54 (Scheme 22). 该催化剂可在用量低至 0.0001 $\mathrm{mol} \%$ 时, $\mathrm{K}_{2} \mathrm{CO}_{3}$ 作碱, $N$-甲基吡咯烷酮为溶剂, $140{ }^{\circ} \mathrm{C}$ 反 应置于空气环境中, 可比较高效催化碘代芳烃与苯硼酸 的偶联, 以及对溴苯乙酮与苯硼酸的偶联, 反应 TON 数 高达 $10^{5}$ 级; 当催化剂用量降至 $1 \times 10^{7} \mathrm{~mol} \%$ 时, 仍可观 察到碘代芳烃的偶联. 该金属化合物共轭 $\pi$ 体系的增加, 显著增强催化剂的催化活性.

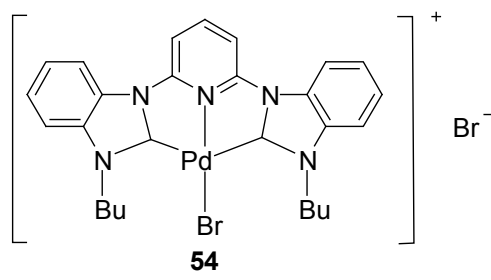

Scheme 22

2009 年, Ghosh 等 ${ }^{[46]}$ 报道合成了一种不同寻常的 N杂环卡宾配体与 Pd 络合形成的 Pd-NHC 催化剂 55, 该 催化剂是五元咪唑环上 $C(3)$ 原子与钯络合成键, 非卡宾 配体仍选用了吡啶环. 催化剂 $\mathbf{5 5}$ 置于敞开环境, 在无 $\mathrm{Cu}$ 无胺活化体系中催化溴代芳烃与末端炔烃的 Sonogashira 偶联反应(Eq. 9), 结果显示该催化剂对于溴

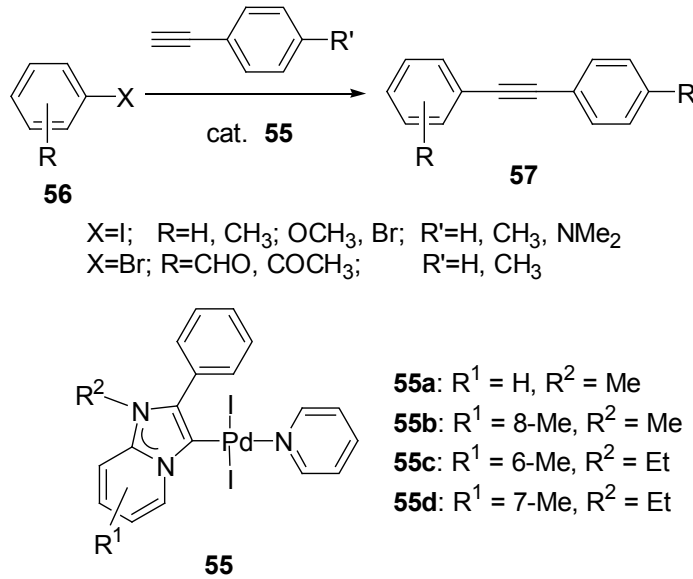

代芳烃具有非常高的催化活性，其中 55a 表现最好，催 化反应收率达到了 99\%; 但对于氯代芳烃表现不佳. 密 度泛函理论计算显示催化剂 $\mathrm{C}(3)$ 原子具有很好的 $\sigma$ 供电 子能力, 能与吡啶环 $\mathrm{N}$ 原子络合紧密.

Baker 等 ${ }^{[47]}$ 报道了三种烷氧基取代的苯并咪唑型 Pd-NHC 催化剂 $\mathbf{5 8} \sim \mathbf{6 0}$ (Scheme 23). 咪唑环上 $\mathrm{N}$ 原子的 取代基团选用了甲基，使之对催化剂整体的空间位阻的 影响降到最低，以此来着重考察卡宾配体与非卡宾配体 (NHC vs. phosphane vs. pyridine)对催化性能的影响. 分 别在 $0.02 \mathrm{~mol} \%$ 和 $0.002 \mathrm{~mol} \%$ 催化剂、 $\mathrm{K}_{2} \mathrm{CO}_{3}$ 作碱、DMF 作溶剂的条件下, 催化剂催化对溴甲苯与苯嗍酸的偶 联, 反应的活性 59>58>60, 但催化活性并无太大差别, 非卡宾配体为 $\mathrm{PPh}_{3}$ 的催化剂 $\mathbf{5 9}$ 活性略好于其他两种.

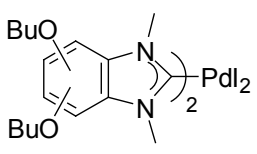

58<smiles></smiles>

59<smiles></smiles>

60

\section{Scheme 23}

使用水相作溶剂参与到 Pd 催化的 Suzuki 反应最近 也引起了深入的研究. 用水代替有机溶剂不仅仅因为水 廉价易得, 安全无毒, 而且用水作溶剂反应后催化剂更 易分离回收. 在催化剂中引入水溶性基团如羧基、磺酸 基、硅基等等都能大大提高催化剂的水溶性. 2010 年, Huynh 等 ${ }^{\left[{ }^{[8]}\right.}$ 在苯并咪唑环的 $\mathrm{N}$ 原子上引入統基，制备出 $\mathrm{NHC}$ 配体和 $\mathrm{S}$ 原子与 $\mathrm{Pd}$ 双配位的双核 $\left(\mathrm{Pd}_{2} \mathrm{~S}_{2}\right)$ 型催化剂 61 (Scheme 24). 该催化剂仅在用量 $0.001 \mathrm{~mol} \%$ 时，在水 相或 dioxane 中, 便可高效催化溴代芳烃底物的偶联, 收率 $>99 \%$, 反应 TON 数高达 100000 .

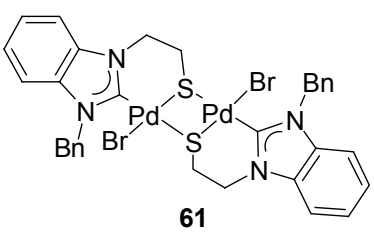

Scheme 24

带有磺化基团配体的 Pd-NHC 催化剂也可以很好的 溶解在水相之中, 其中最有效的配体之一是 TPPTS(三 苯基膦三间磺酸钠). Türkmen 等 ${ }^{[49]}$ 报道了一种 Pd 原子 与 TPPTS 配体相连的苯并咪唑型 Pd-NHC 催化剂 62 (Scheme 25), 在水相环境中用 $1 \mathrm{~mol} \%$ 催化剂催化氯代 
芳烃与苯嗍酸的偶联反应时展示出了非常高的活性.

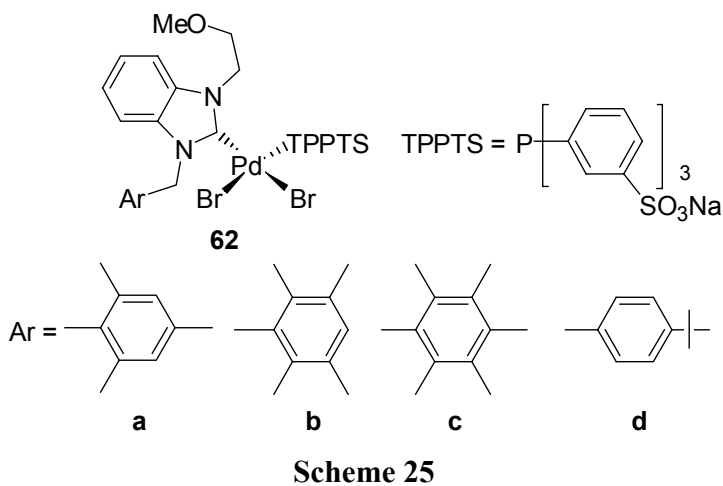

$\mathrm{Liu}$ 等 ${ }^{[50]}$ 将吡啶连接到苯并咪唑环的 $\mathrm{N}$ 原子上形成 双吡啶与 NHC 配体三配位的 NCN 型 Pd-NHC 催化剂 63 (Scheme 26). 他们以澳苯与苯硼酸的偶联为实验得 出最适合该催化剂反应的体系是 $\mathrm{KOH}$ 作碱, $V(\mathrm{MeOH}): V\left(\mathrm{H}_{2} \mathrm{O}\right)=5: 1$ 作溶剂, 仅需 $0.2 \mathrm{~mol} \%$ 的催 化剂用量即可催化一系列溴代底物的偶联反应.

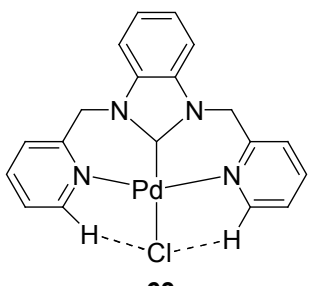

63

\section{Scheme 26}

Zhang 等 ${ }^{[51]}$ 由 1,2-环已二胺为起始物反应引入对称 的苯并咪唑结构 Pd-NHC 催化剂 64 (Scheme 27). 该催 化剂采用了非常大位阻的取代基团，可能对催化剂活性 有些影响, 因而该催化剂对溴代以及氯代底物表现一 般. 但对溴荟与芳基硼酸的偶联却有特殊的选择性, 催 化溴萗和萗硼酸反应收率可达 $99 \%$.

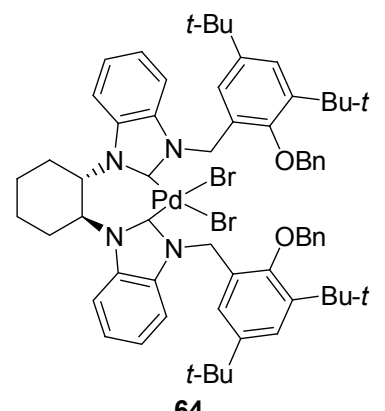

Scheme 27

柳湘晴课题组 ${ }^{[52]}$ 报道了乙氧基桥连的苯并咪唑型 的开链双核 Pd-NHC 催化剂 65 (Scheme 28), 同时引入 了乙腈作为非卡宾配体, 其显著特点是对空气非常稳 定. 他们使用 $0.1 \mathrm{~mol} \%$ 催化剂用量, 在三水合磷酸钾或
氢氧化钾作碱, $V(\mathrm{MeOH}): V\left(\mathrm{H}_{2} \mathrm{O}\right)=1: 1$ 条件下, $50{ }^{\circ} \mathrm{C}$ 置于空气环境中可以高效催化对溴甲苯与苯硼酸的偶 联; 而后, 他们又研究了氯代芳烃的偶联, 发现加入 $\mathrm{TBAB}$ 或 $\mathrm{PPh}_{3}$ 作为助催化剂后，可以显著地增加反应收 率.

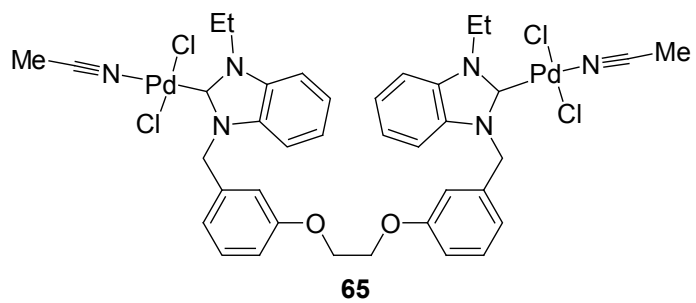

Scheme 28

在该类催化剂中，桥连基团的结构、碳链的长短以 及空间和立体效应都会影响到催化剂的活性. 因此 2013 年, 他们课题组 ${ }^{[53]}$ 又报道了正己基桥连的苯并咪唑型开 链双核 Pd-NHC 催化剂 66 催化对溴甲苯与苯硼酸的偶 联(Scheme 29).

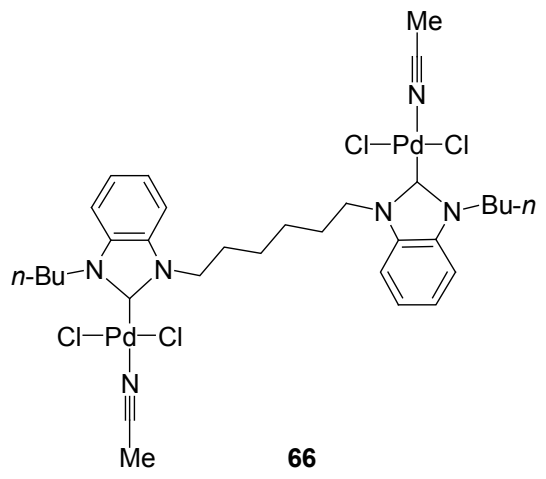

Scheme 29

他们发现将反应置于空气环境中, 三水合磷酸钾作 碱, 在水相溶剂中加入 $\mathrm{TBAB}$ 可以大幅增加反应的收 率; 并且不仅仅催化对溴甲苯很高效，对一些活化或是 未活化的氯代芳烃以及带有大位阻基团的芳基硼酸的 偶联也很有效. 但遗憾的是, 和之前的工作相比, 虽然 改变了桥连基团，但是催化剂的活性并没有明显的改 善. 作者认为可能是引入的已基碳链过长，导致两个钯 核距离过远反而不利于配位. 因此这种开链双核类的催 化剂还需进一步探索. 不仅如此, 催化剂 66 还可在 110 ${ }^{\circ} \mathrm{C}$ 条件下高效催化溴代芳烃与苯乙烯的 Heck 反应(Eq 10).

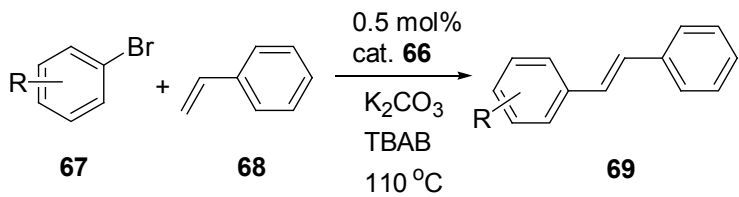


Doucet 等 ${ }^{[54]}$ 比较了他们合成的一系列 Pd-NHC 在选 择性的催化吡咯类化合物的 $\mathrm{C}(2)$ 或 $\mathrm{C}(5)$ 原子上进而活 化 $\mathrm{C}-\mathrm{H}$ 键, 可以和连有吸电子基团的氯代芳烃进行交 叉偶联反应，他们在苯并咪唑结构的卡宾配体基础上, 通过改变 $\mathrm{N}$ 原子所连基团合成了 9 种不同结构催化剂, 并催化吡咯衍生物与氯代芳烃的偶联(Eq. 11), 催化剂 用量 $1 \mathrm{~mol} \%, \mathrm{KOAc}$ 作碱, DMAc 作溶剂, $150{ }^{\circ} \mathrm{C}$ 反应 20 $\mathrm{h}$ ，反应收率显示 $\mathrm{N}$ 原子连有更大空间位阻基团的催化 剂 70 74 活性更高. 这也是第一次有报道利用 Pd-NHC 催化剂直接活化 $\mathrm{C}-\mathrm{H}$ 键和连有吸电子基团的氯代芳烃 进行交叉偶联反应.
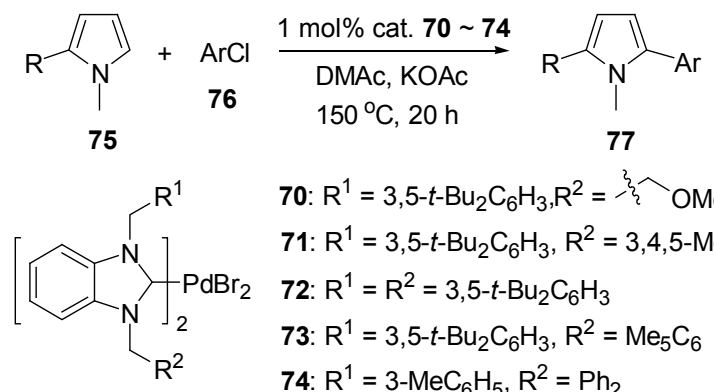

$$
\begin{aligned}
& \text { 70: } \mathrm{R}^{1}=3,5-t-\mathrm{Bu}_{2} \mathrm{C}_{6} \mathrm{H}_{3}, \mathrm{R}^{2}=\text { 约 } \mathrm{OMe} \\
& \text { 71: } \mathrm{R}^{1}=3,5-t-\mathrm{Bu}_{2} \mathrm{C}_{6} \mathrm{H}_{3}, \mathrm{R}^{2}=3,4,5-\mathrm{Me}_{3} \mathrm{C}_{6} \mathrm{H}_{2} \\
& \text { 72: } \mathrm{R}^{1}=\mathrm{R}^{2}=3,5-t-\mathrm{Bu}_{2} \mathrm{C}_{6} \mathrm{H}_{3} \\
& \text { 73: } \mathrm{R}^{1}=3,5-t-\mathrm{Bu}_{2} \mathrm{C}_{6} \mathrm{H}_{3}, \mathrm{R}^{2}=\mathrm{Me}_{5} \mathrm{C}_{6} \\
& \text { 74: } \mathrm{R}^{1}=3-\mathrm{MeC}_{6} \mathrm{H}_{5}, \mathrm{R}^{2}=\mathrm{Ph}_{2}
\end{aligned}
$$

\section{4 六元 $N$ 杂环以及其它杂环结构类型 Pd-NHC 催化剂}

摆脱传统五元 $\mathrm{N}$ 杂环咪唑结构卡宾的束缚, 科学家 们尝试合成了多种不同类型环状结构的卡宾配体, 并将 其应用至金属催化反应中, 其中一部分催化剂在催化多 种交叉偶联反应都表现出不错的性能. 2005 年, Herrmann 等 ${ }^{[55]}$ 合成报道了一种并非基于传统的五元咪 唑环类型 Pd-NHC 型催化剂. 该催化剂具有饱和的四氢 嘧啶六元 $\mathrm{N}$ 杂环卡宾结构, 同时运用膦配体作为非卡宾 配体. 他们发现催化剂 78 是一种对活化和未活化溴代 芳烃都非常高效的催化剂(Scheme 30), 当在 0.0001 mol\%用量下, 可以 $100 \%$ 催化对溴苯乙酮与苯硼酸的偶 联, 反应 TON 数可达 $10^{6}$. 但对于同样结构的 NHC 配体, 若减少一个膦配体得到的催化剂 $\mathbf{7 9}$, 在相同反应条件下 反应收率仅为 $63 \%$. 作者认为催化剂 78 比 79 多一个膦 配体, 因而具有更强的 $\sigma$ 供电子能力, 更易形成活性物 种. 同时他们观察到反应中催化剂 79 比 78 更快出现钯 黑, 也说明了更富电子的催化剂 $\mathbf{7 8}$ 稳定性也相对更好.
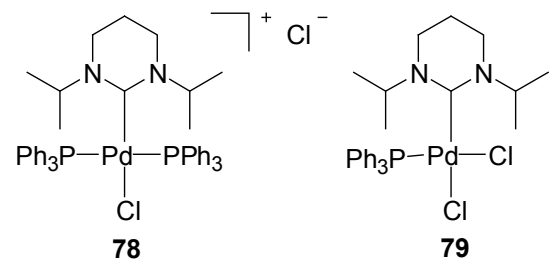

Scheme 30
同年，他们 ${ }^{[56]}$ 又报道了一种被他们称作 rNHC (remote NHC)配体与钯配位形成的 Pd-rNHC 型催化剂 80 (Scheme 31), 这类型的催化剂目前报道还非常少。该催 化剂的特点是环上 $\mathrm{N}$ 原子与卡宾碳原子相隔较远, 通常 在对位. 他们也将该催化剂用于 Suzuki 反应验证其催化 效率. 惊喜的是, 催化剂 $\mathbf{8 0}$ 在催化活化的溴代芳烃如对 溴苯乙酮与苯硼酸的偶联时，仅用 $0.0001 \mathrm{~mol} \%$ ，就可 以得到 $>99 \%$ 的收率，反应 TON 数高达 $10^{6}$. 降低催化 剂用量至 $10^{-5} \mathrm{~mol} \%$, 反应收率依然有 $32 \%$, 反应 $\mathrm{TON}$ 数为 $3.2 \times 10^{6}$. 当催化澳苯与苯硼酸的偶联时, 使用 0.1 mol\%用量，反应仅 $10 \mathrm{~min}$ 时，收率就可达 $95 \%$; 使用 $0.001 \mathrm{~mol} \%$ 用量，延长反应时间，最终反应收率也可达 98\%. 同样催化剂在低用量下, 催化溴代芳烃的 Heck 反 应，也能达到很好的收率。

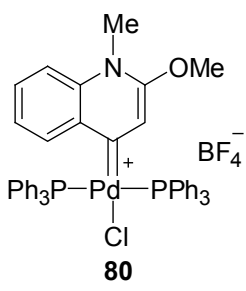

Scheme 31

在此基础上, Herrmann 小组 ${ }^{[57]}$ 对该催化剂的结构进 行进一步改造, 又合成了四种源于吡啶、喹啉、叮啶结 构的 Pd-rNHC 催化剂 81 84 (Scheme 32), 这四种催化 剂在催化活泼的澳代芳烃如对溴苯乙酮的反应时，用量 低至 $0.001 \mathrm{~mol} \%$, 催化反应收率均可大于 $99 \%$; 催化剂 的用量可以进一步降至 $0.0001 \mathrm{~mol} \%$.
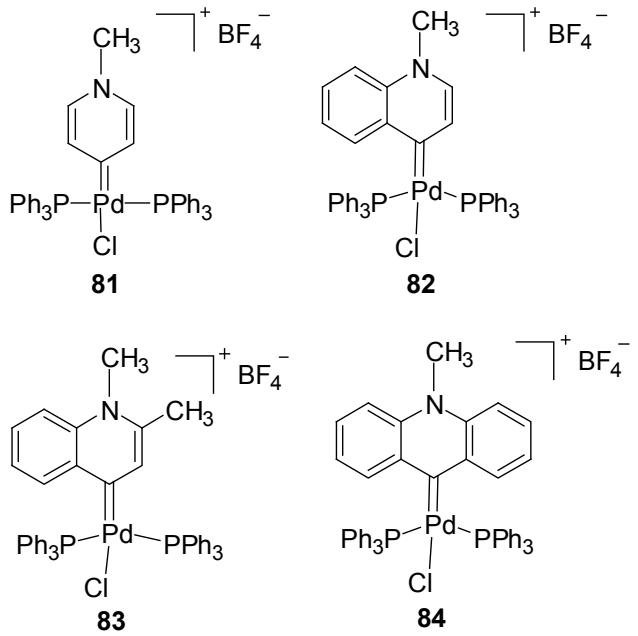

Scheme 32

2009 年, Ghosh 等 ${ }^{[58]}$ 将咪唑啉以及苯三唑结构作为 $\mathrm{N}$-杂环卡宾配体与 Pd 络合形成的一系列 Pd-PEPPSI 类 型催化剂用于 Hiyama 反应和 Sonogashira 反应中. 催化 
剂 85 86 合成简单方便(Scheme 33), 并且能在敞开体 系中高效催化溴代芳烃与有机硅化合物的 Hiyama 偶联 反应，反应不需氟活化剂的加入; 该系列催化剂对溴代 芳烃的 Sonogashira 反应也有着非常高的催化活性, 反 应也不需 $\mathrm{Cu}$ 试剂的作用.

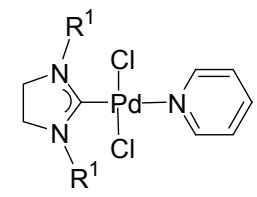

85a: $\mathrm{R}^{1}=2,6-i-\mathrm{Pr}_{2} \mathrm{C}_{6} \mathrm{H}_{3}$

85b: $\mathrm{R}^{1}=2,6-\mathrm{Et}_{2} \mathrm{C}_{6} \mathrm{H}_{3}$ 85c: $R^{1}=2,4,6-M_{3} \mathrm{C}_{6} \mathrm{H}_{2}$ 85d: $R^{1}=2,6-M_{2} \mathrm{C}_{6} \mathrm{H}_{3}$

Scheme 3

Luo 等 ${ }^{[59]}$ 合成了一种源于咖啡因结构的 NHC 配体 与钯形成的二聚体形式催化剂 87 (Scheme 34), 并且在 水相中催化溴代芳烃与苯硼酸的偶联. 反应结果显示在 $\mathrm{H}_{2} \mathrm{O}$ 作溶剂、 $\mathrm{NaO} t-\mathrm{Bu}$ 作碱、 $25{ }^{\circ} \mathrm{C}$ 条件下, 催化对溴甲 苯与苯硼酸偶联反应, 收率可达 $88 \%$, 升高温度到 65 ${ }^{\circ} \mathrm{C} 、 \mathrm{KOH}$ 作碱，反应收率可提升至 $95 \%$. 作者又发现 2 $\mathrm{mol} \%$ 该催化剂在水相中催化对溴硝基苯与苯乙炔的 Sonogashira 反应时, 在 $\mathrm{CuI}$ 参与下, 反应并不能很好的 发生, 但把溶剂体积比调整为 $V\left(\mathrm{H}_{2} \mathrm{O}\right): V($ Brij 30) $=2$ : 1 时, Brij 30(四聚乙二醇单月桂醚)作为非离子表面活性 剂，反应收率有了极大提升; 同样在催化 Heck 反应时, 溶剂体系为 $V\left(\mathrm{H}_{2} \mathrm{O}\right): V(\mathrm{Brij} 30)=2: 1$ 亦能显著提高反 应的收率.

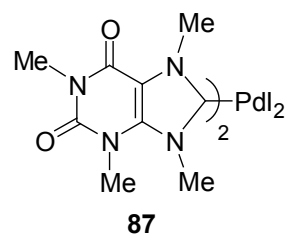

Scheme 34

2011 年, Cavell 等 ${ }^{[60]}$ 合成了一系列新颖的零价钯 $\operatorname{Pd}(0)(\mathrm{dvtms})-\mathrm{NHC}$ 催化剂 $(\mathrm{dvtms}=$ 乙烯基四甲基二硅氧 烷)88 94 (Scheme 35), 他们将 $0.1 \mathrm{~mol} \%$ 此系列催化剂 用于 Heck 反应中, 以对溴苯乙酮和正丁基丙烯酸酯的 反应作为催化剂活性探索实验. 他们首先比较了配体 $\mathrm{N}$ 杂环上碳原子个数对催化活性的影响, 当 $\mathrm{N}$ 原子所连基 团相同时，七元环结构催化剂活性显著高于六元环催化 剂, 其中催化剂 92,93 催化反应收率可至 100\%, 而对应 的 88 和 89 催化反应收率几乎只有一半左右; 后他们又 比较 $\mathrm{N}$ 原子上所连取代基的不同对反应活性影响, 结果 显示当配体结构为六元环时, $\mathrm{R}$ 和 $\mathrm{R}$ 基团的改变对催化
活性影响不大，而对配体结构为七元环催化剂的活性则 影响很大.

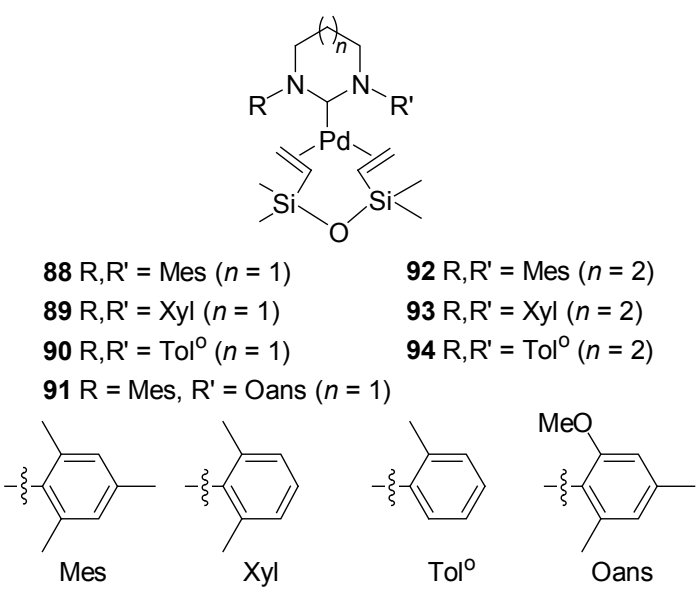

Scheme 35

Siemeling 等 ${ }^{[61]}$ 也报道了一种非传统 Pd-NHC 型催 化剂 95 (Scheme 36), 将原有的五元咪唑环上 C(4),C(5) 原子用二茂铁基团取代得到的一种新型钯催化剂 cis$\left[\mathrm{PdCl}_{2}(1-\mathrm{Np})\left(\mathrm{PPh}_{3}\right)\right]$. 该催化剂在极少用量的情况下就 可催化多种溴代以及氯代芳烃与苯硼酸的偶联，例如在 $0.0001 \mathrm{~mol} \%$ 用量下催化溴苯的偶联，反应收率可达 $95 \%$, 反应 $\mathrm{TON}$ 数高达 $9.5 \times 10^{5}$.

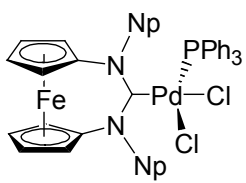

95

Scheme 36

Newman 等 ${ }^{[62]}$ 以 1,2,2-三甲基环戊烷-1,3-二胺和 2-(二苯基磷)苯甲醛为起始物合成了一种双膦与六元 $\mathrm{N}$ 杂环卡宾配体与钯配位形成的 Pd-NHC 催化剂 96 (Scheme 37). 该催化剂对活化及未活化的溴代底物展示 出了非常好的催化性能，但对氯代芳烃则无催化活性.

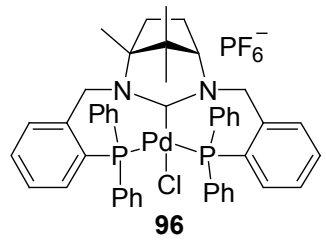

Scheme 37

受到 Organ 等工作的启发, $\mathrm{Tu}$ 等 ${ }^{[63]}$ 通过修饰 $\mathrm{NHC}$ 配体上咪唑环的结构，引入菜基团，合成了催化剂 97. 利用该催化剂他们考察了多种大位阻的卤代芳烃和大 位阻的芳基硼酸的偶联反应. 以 2-甲氧基溴萘与 2,6-二 甲基苯硣酸的偶联反应为例，他们发现，在该催化体系 
中不同的碱以及溶剂的选择对反应收率影响很大. 碱性 越强反应产率越好，在叔丁醇钾和甲苯条件下，使用 0.5 $\mathrm{mol} \%$ 的催化剂即可达到 $>99 \%$ 的反应收率. 同 Organ 等 合成的 PEPPSI 催化剂体系一样, 催化剂 97 对于多种类 型大位阻底物具有适用广谱性, 特别是对于多氯取代底 物, 97 可高效催化其与大位阻硼酸的偶联(Eq. 12), 反应 收率可至 $90 \%$ 以上; 此外, 除去 $\mathrm{NHC}$ 配体的影响, 修饰 配体结构对催化剂整体性能影响很大. 作者认为荎结构 基团影响了 $\mathrm{C}(2)$ 原子与 $\mathrm{Pd}$ 的配位.<smiles>[R]Cc1cc[R](O)c([R])c1[R]</smiles>

98

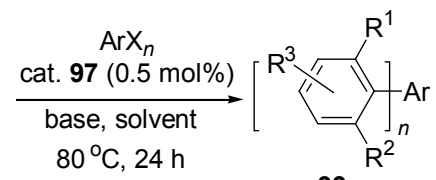

99

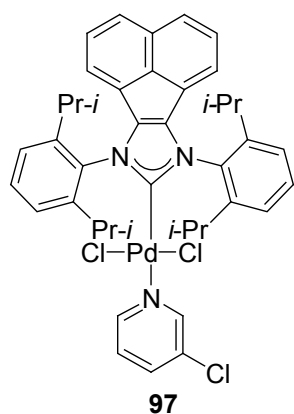

Peris 等 ${ }^{[64]}$ 报道了一种新颖的双金属络合的 PdNHC-Ir 催化剂 100 (Scheme 38), 金属 Ir 参与形成 N 杂 环卡宾. 该催化剂在催化对溴苯乙酮与苯硼酸的偶联 时, 产物并不仅仅是偶联产物, 而是随着反应时间的增 加, 对溴苯乙酮的脱溴产物逐渐减少, 还原产物逐渐增 加, 偶联产物在反应时间 $0.5 \mathrm{~h}$ 达到最大, 随后逐渐减 少, 随着反应时间的增加, 反应获得的偶联产物渐渐被 还原. 而他们合成的另一种 Pd-NHC-Ir 催化剂 101 在同 样反应条件下，则不会出现这些现象，但随着反应时间 的延长，偶联产物也会逐渐被还原.
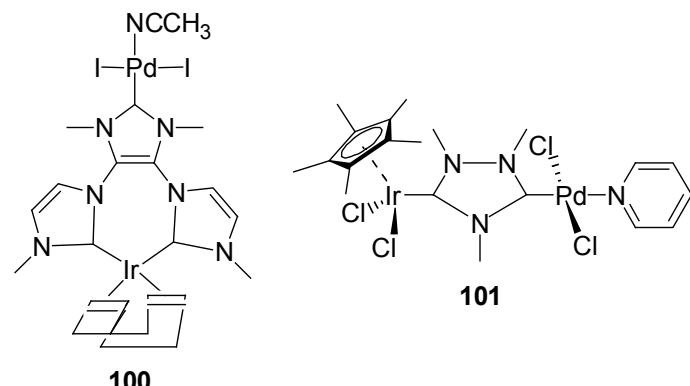

\section{Scheme 38}

2013 年, Türkmen 等 ${ }^{[65]}$ 在哌啶咪唑配体与 $\mathrm{Pd}$ 络合基 础上, 考量了三种非卡宾配体吡嗪、吡啶, 以及哌啶咪 唑对催化剂整体性能的影响. 以 $1 \mathrm{~mol} \%$ 催化剂用量催
化对氯苯乙酮与苯硣酸的 Suzuki 偶联反应为例, 催化剂 104 催化反应收率明显低于 102 和 103 (Scheme 39). 作 者认为是哌啶咪唑配体的供电子能力弱于吡嗪和吡啶. 而催化剂 102 则展现出相对更高的活性, 特别对于催化 氯代芳烃底物，收率很高，催化剂用量甚至可以低至 $0.001 \mathrm{~mol} \%$. 他们又将催化剂 102 用于 Kumada 偶联反 应中， $2 \mathrm{~mol} \%$ 催化剂催化氯代芳烃与溴化苯基镁的偶 联，反应收率在 $60 \%$ 以上. 关于催化剂 102 的其他偶联 反应的探索仍在进行中.
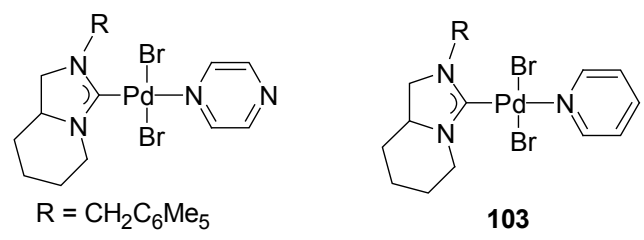

102

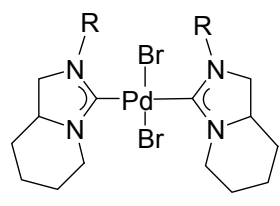

104

Scheme 39

\section{3 结论及展望}

本文总结了 2010 年来新发展起来的不同结构类型 的 NHC 配体与 Pd 络合形成的 Pd-NHC 催化剂在催化多 种不同交叉偶联反应中的催化效果. 特别关注催化剂结 构与催化剂效果之间潜在的联系. Pd 催化交叉偶联反应 现已成为重要的构建 $\mathrm{C}-\mathrm{C}$ 键, 生成联芳基化合物方法 之一，探索多种类型的 Pd-NHC 催化剂并研究其在偶联 反应中的催化活性具有现实的意义. 而相比于膦配体 等, $\mathrm{N}$-杂环卡宾配体以其众多优点正被广泛深入的研究. 目前在材料、液晶以及医药中间体等领域对联芳基化合 物的需求要求高效、环保、稳定性高的 Pd 催化剂体系, Pd-NHC 催化剂体系一个显著的优点便是制备简单、毒 性小，这为将来工业应用也提供了一定的可能性.

\section{References}

[1] Ofele, K. J. Organomet. Chem. 1968, 12, P42.

[2] Wanzlick, H.-W.; Schönherr, H.-J. Angew. Chem. 1968, 80, 154.

[3] (a) Arduengo, A. J.; Harlow, R. L.; Kline, M. J. Am. Chem. Soc. 1991, 113, 361

(b) Arduengo, A. J. Acc. Chem. Res. 1999, 32, 913.

[4] Scholl, M; Ding, S; Lee, C.-W.; Grubbs, R. H. Org. Lett. 1999, 1, 953.

[5] Jiang, L.; Li, Z. N.; Zhao, D. F. Chin. J. Org. Chem. 2010, 30, 200 (in Chinese).

(姜岗, 李争宁, 赵德峰, 有机化学, 2010, 30, 200.)

[6] Correa, A.; Nolan, S. P.; Cavallo, L. Springer Berlin Heidelberg 2011, 131.

[7] Budagumpi, S.; Haque, R. A.; Salman, A. W. Coord. Chem. Rev. 
2012, 256, 1787.

[8] Yuan, D.; Huynh, H. V. Molecules 2012, 17, 2491.

[9] Weskamp, T.; Böhm, V. P. W.; Herrmann, W. A. J. Organomet. Chem. 1999. 585. 348.

[10] Zhang, C.-M.; Huang J.-K.; Trudell, M. L.; Nolan, S. P. J. Org. Chem. 1999, 64, 3804.

[11] (a) Marion, N.; Nolan, S. P. Acc. Chem. Res. 2008, 41, 1440.

(b) Navarro, O.; Kelly, R. A.; Nolan, S. P. J. Am. Chem. Soc. 2003, 125, 16194.

(c) Marion, N.; Navarro, O.; Mei, J.; Stevens, E. D.; Scott, N. M.; Nolan, S. P. J . Am. Chem. Soc. 2006, 128, 4101.

[12] Wu, L.; Drinkel, E.; Gaggia, F.; Capolicchio, S.; Linden, A.; Falivene, L.; Dorta, R. Chem. Eur. J. 2011, 17, 12886.

[13] O'Brien, C. J.; Kantchev, E. A. B.; Valente, C., Hadei, N.; Chass, G. A.; Lough, A.; Organ, M. G. Chem. Eur. J. 2006, 12, 4743.

[14] O'Keefe, B. M.; Simmons, N.; Martin, S. F. Org. Lett. 2008, 10, 5301.

[15] Organ, M. G.; Abdel-Hadi, M.; Avola, S.; Dubovyk, I.; Hadei, N.; Kantchev, E. A. B.; Valente, C. Chem. Eur. J. 2008, 14, 2443.

[16] Valente, C.; Belowich, M. E.; Hadei, N.; Organ, M. G. Eur. J. Org. Chem. 2010, 23, 4343.

[17] Chartoire, A.; Frogneux, X.; Boreux, A.; Slawin, A. M.; Nolan, S. P. Organometallics 2012, 31, 6947.

[18] Zhang, X.-M.; Xia, Q.-Q.; Chen, W.-Z. Dalton Trans. 2009, 7045.

[19] Tang, Y.-Q.; Lu, J.-M.; Shao, L.-X. J. Organomet. Chem. 2011, 696, 3741.

[20] Gu, Z.-S.; Shao, L.-X.; Lu, J.-M. J. Organomet. Chem. 2012, 700, 132.

[21] Lin, X.-F.; Li, Y.; Li, S.-Y.; Xiao, Z.-K.; Lu, J.-M. Tetrahedron 2012, 68, 5806.

[22] Yeung, A. D.; Ng, P. S.; Huynh, H. V. J. Organomet. Chem. 2011, 696, 112.

[23] Herrmann, W. A.; Reisinger, C.-P.; Spiegler, M. J. Organomet. Chem. 1998, 557, 93.

[24] Jin, Z.; Guo, S. X.; Gu, X. P.; Qiu, L. L.; Song, H. B.; Fang, J. X. Adv. Synth. Catal. 2009, 351, 1575.

[25] Jin, Z.; Gu, X.-P.; Qiu, L.-L.; Wu G.-P.; Song, H.-B.; Fang, J.-X. J. Organomet. Chem. 2011, 696, 859.

[26] Hashmi, A. S. K.; Lothschütz, C., Böhling, C.; Rominger, F. Organometallics 2011, 30, 2411.

[27] Saito, S.; Saika, M.; Yamasaki, R.; Azumaya, I.; Masu, H. Organometallics 2011, 30, 1366.

[28] Yu, H.; Wan, L.; Cai, C. J. Fluorine Chem. 2012, 144, 143.

[29] Roy, S.; Plenio, H. Adv. Synth. Catal. 2010, 352, 1014.

[30] Hartmann, C. E.; Nolan, S. P.; Cazin, C. S. J. Organometallics 2009, 28, 2915.

[31] Ma, M.-T.; Lu, J.-M. Appl. Organomet. Chem. 2012, 26, 175.

[32] Chartoire, A.; Boreux, A.; Martin, A. R.; Nolan, S. P. RSC Adv. 2013, 3, 3840 .

[33] Peñafiel, I.; Pastor, I. M.; Yus, M. Eur. J. Org. Chem. 2013, 1479.

[34] Gstöttmayr, C. W.; Böhm, V. P.; Herdtweck, E.; Grosche, M.; Herrmann, W. A. Angew. Chem., Int. Ed. 2002, 41, 1363.

[35] Fu, C.-F.; Lee, C.-C.; Liu, Y.-H.; Peng, S.-M.; Warsink, S.; Elsevier,
C. J.; Chen, J.-T.; Liu, S.-T. Inorg. Chem. 2010, 49, 3011.

[36] Ellul, C. E.; Reed, G.; Mahon, M. F.; Pascu, S. I.; Whittlesey, M. K. Organometallics 2010, 29, 4097.

[37] Chang, Y.-H.; Liu, Z.-Y.; Liu, Y.-H.; Peng, S.-M.; Chen, J.-T.; Liu, S.-T. Dalton Trans. 2011, 40, 489.

[38] Zhang, W.; Zhang, X.; Luo, M. Chin. J. Chem. 2012, 30, 1423.

[39] Steel, P. G.; Teasdale, W. T. Tetrahedron Lett. 2004, 45, 8977.

[40] Churruca, F.; SanMartin, R.; Inés, B.; Tellitu, I.; Domínguez, E. Adv. Synth. Catal. 2006, 348, 1836.

[41] Nan, G.; Rao, B.; Luo, M. ARKIVOC 2011, 2, 29.

[42] Blakemore, J. D.; Chalkley, M. J.; Farnaby, J. H.; Guard, L. M.; Hazari, N.; Incarvito, C. D.; Suh, H. W. Organometallics 2011, 30, 1818.

[43] Godoy, F.; Segarra, C.; Poyatos, M.; Peris, E. Organometallics 2011, 30, 684.

[44] Micksch, M.; Strassner, T. Eur. J. Inorg. Chem. 2012, 5872.

[45] Tu, T.; Malineni, J.; Dötz, K. H. Adv. Synth. Catal. 2008, 350, 1791.

[46] John, A.; Shaikh, M. M.; Ghosh, P. Dalton Trans. 2009, 10581

[47] Baker, M. V.; Brown, D. H.; Simpson, P. V.; Skelton, B. W.; White, A. H. Eur. J. Inorg. Chem. 2009, 1977.

[48] Yuan, D.; Huynh, H. V. Organometallics 2010, 29, 6020.

[49] Türkmen, H.; Pelit, L.; Çetinkaya, B. J . Mol. Catal. A: Chem. 2011, $348,88$.

[50] Liu, Q.-X.; Li, H.-L.; Zhao, X.-J.; Ge, S.-S.; Shi, M.-C.; Shen, G.; Zang, Y.; Wang, X.-G. Inorg. Chim. Acta 2011, 376, 437.

[51] Shigeng, G.; Tang, J.; Zhang, D.; Wang, Q.; Chen, Z.; Weng, L. J. Organomet. Chem. 2012, 700, 223.

[52] Liu, Q.-X.; Wang, H.; Zhao, X.-J.; Yao, Z.-Q.; Wang, Z.-Q.; Chen, A.-H.; Wang, X.-G. CrystEngComm 2012, 14, 5330.

[53] Liu, Q.-X.; Zhang, W.; Zhao, X.-J.; Zhao, Z.-X.; Shi, M.-C.; Wang, X.-G. Eur. J. Org. Chem. 2013, 1253.

[54] Özdemir, I.; Gürbüz, N.; Kaloğlu, N.; Doğan, Ö.; Kaloğlu, M.; Bruneau, C.; Doucet, H. Beilstein J. Org. Chem. 2013, 9, 303.

[55] Schneider, S. K.; Herrmann, W. A.; Herdtweck, E. J . Mol. Catal. A: Chem. 2006, 245, 248.

[56] Schneider, S. K.; Roembke, P.; Julius, G. R.; Loschen, C.; Raubenheimer, H. G.; Frenking, G.; Herrmann, W. A. Eur. J. Inorg. Chem. 2005, 2973.

[57] Schneider, S. K.; Roembke, P.; Julius, G. R.; Raubenheimer, H. G.; Herrmann, W. A. Adv. Synth. Catal. 2006, 348, 1862.

[58] Dash, C.; Shaikh, M. M.; Ghosh, P. Eur. J. Inorg. Chem. 2009, 1608.

[59] Luo, F.-T.; Lo, H.-K. J. Organomet. Chem. 2011, 696, 1262.

[60] Dunsford, J. J.; Cavell, K. J. Dalton Trans. 2011, 40, 9131

[61] Siemeling, U.; Färber, C.; Bruhn, C.; Fürmeier, S.; Schulz, T.; Kurlemann, M.; Tripp, S. Eur. J. Inorg. Chem. 2012, 1413.

[62] Newman, P. D.; Cavell, K. J.; Kariuki, B. M. Dalton Trans. 2012, 41,12395 .

[63] Tu, T.; Sun, Z.; Fang, W.; Xu, M.; Zhou, Y. Org. Lett. 2012, 14, 4250.

[64] Gonell, S.; Poyatos, M.; Mata, J. A.; Peris, E. Organometallics 2012, 31, 5606 .

[65] Türkmen, H.; Kani, İ. Appl. Organomet. Chem. 2013, 27, 489.

(Cheng, F.) 